\title{
Siderophore and indolic acid production by Paenibacillus triticisoli BJ-18 and their plant growth-promoting and antimicrobe abilities
}

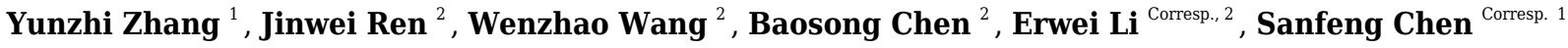 \\ ${ }^{1}$ State Key Laboratory for Agrobiotechnology, College of Biological Sciences, China Agricultural University, Beijing, People's Republic of China \\ 2 State Key Laboratory of Mycology, Institute of Microbiology, Chinese Academy of Sciences, Beijing, People's Republic of China \\ Corresponding Authors: Erwei Li, Sanfeng Chen \\ Email address: liew@im.ac.cn, chensf@cau.edu.cn
}

Paenibacillus triticisoli $\mathrm{BJ}-18$, a $\mathrm{N}_{2}$-fixing bacterium, is able to promote plant growth, but the secondary metabolites that may play a role in promoting plant growth have never been characterized. In this study, untargeted metabolomics profiling of $P$. triticisoli BJ-18 indicated the existence of 101 known compounds, including $\mathrm{N}^{2}$-acetyl ornithine, which is the precursor of siderophores, plant growth regulators such as trehalose 6-phosphate, betaine and trigonelline, and other bioactive molecules such as oxymatrine, diosmetin, luotonin A, (-)-caryophyllene oxide and tetrahydrocurcumin. In addition, six compounds were also isolated from $P$. triticisoli BJ-18 using a combination of silica gel chromatography, sephadex LH-20, octadecyl silane (ODS), and high-performance liquid chromatography (HPLC). The compound structures were further analyzed by Nuclear Magnetic Resonance (NMR), Mass Spectrometry (MS), and Electronic Circular Dichroism (ECD). The six compounds included three classical siderophore fusarinines identified as deshydroxylferritriacetylfusigen, desferritriacetylfusigen, and triacetylfusigen, and three indolic acids identified as paenibacillic acid A, 3-indoleacetic acid (IAA), and 3indolepropionic acid (IPA). Both deshydroxylferritriacetylfusigen and paenibacillic acid A have new structures. Fusarinines, which normally occur in fungi, were isolated from bacterium for the first time in this study. Both siderophores (compounds $\mathbf{1}$ and $\mathbf{2}$ ) showed antimicrobial activity against Escherichia coli, Staphylococcus aureus and Bacillus subtilis, but did not show obvious inhibitory activity against yeast Candida albicans. Whereas triacetylfusigen (compound $\mathbf{3}$ ) showed no antibiosis activity against these test microorganisms. Paenibacillic acid A, IAA, and IPA were shown to promote the growth of plant shoots and roots, and paenibacillic acid $A$ also showed antimicrobial activity against $S$. aureus. Our study demonstrates that siderophores and indolic acids may play an important role in plant growth promotion by P. triticisoli BJ-18. 


\section{Siderophore and indolic acid production by Paenibacillus triticisoli BJ-18 and their plant growth- promoting and antimicrobe abilities}

1 Yunzhi Zhang ${ }^{1 \dagger}$, Jinwei Ren ${ }^{2}$, Wenzhao Wang ${ }^{2}$, Baosong Chen ${ }^{2}$, Erwei Li ${ }^{2 *}$ and Sanfeng 2 Chen ${ }^{1, *}$

3

$4{ }^{1}$ State Key Laboratory for Agrobiotechnology and College of Biological Sciences, China

5 Agricultural University, Beijing, P. R. China

$6{ }^{2}$ State Key Laboratory of Mycology, Institute of Microbiology, Chinese Academy of Sciences, 7 Beijing, P. R. China

9 Corresponding Author:

10 Sanfeng Chen ${ }^{1}$

11 State Key Laboratory for Agrobiotechnology and College of Biological Sciences, China 12 Agricultural University, Beijing, P. R. China

13 Email address: chensf@,cau.edu.cn

Erwei $\mathrm{Li}^{2}$

State Key Laboratory of Mycology, Institute of Microbiology, Chinese Academy of Sciences, 17 Beijing, P. R. China

Email address: $\underline{\text { liew@im.ac.cn }}$ 


\section{Abstract}

Paenibacillus triticisoli $\mathrm{BJ}-18$, a $\mathrm{N}_{2}$-fixing bacterium, is able to promote plant growth, but the secondary metabolites that may play a role in promoting plant growth have never been characterized. In this study, untargeted metabolomics profiling of P. triticisoli BJ-18 indicated the existence of 101 known compounds, including $\mathrm{N}^{2}$-acetyl ornithine, which is the precursor of siderophores, plant growth regulators such as trehalose 6-phosphate, betaine and trigonelline, and other bioactive molecules such as oxymatrine, diosmetin, luotonin A, (-)-caryophyllene oxide and tetrahydrocurcumin. In addition, six compounds were also isolated from P. triticisoli BJ-18 using a combination of silica gel chromatography, sephadex LH-20, octadecyl silane (ODS), and high-performance liquid chromatography (HPLC). The compound structures were further analyzed by Nuclear Magnetic Resonance (NMR), Mass Spectrometry (MS), and Electronic Circular Dichroism (ECD). The six compounds included three classical siderophore fusarinines identified as deshydroxylferritriacetylfusigen, desferritriacetylfusigen, and triacetylfusigen, and three indolic acids identified as paenibacillic acid A, 3-indoleacetic acid (IAA), and 3indolepropionic acid (IPA). Both deshydroxylferritriacetylfusigen and paenibacillic acid A have new structures. Fusarinines, which normally occur in fungi, were isolated from bacterium for the first time in this study. Both siderophores (compounds 1 and 2) showed antimicrobial activity against Escherichia coli, Staphylococcus aureus and Bacillus subtilis, but did not show obvious inhibitory activity against yeast Candida albicans. Whereas triacetylfusigen (compound 3) showed no antibiosis activity against these test microorganisms. Paenibacillic acid A, IAA, and IPA were shown to promote the growth of plant shoots and roots, and paenibacillic acid A also showed antimicrobial activity against $S$. aureus. Our study demonstrates that siderophores and indolic acids may play an important role in plant growth promotion by P. triticisoli BJ-18.

\section{Introduction}

Plant growth-promoting bacteria (PGPB) have great usage as agricultural inoculants, such as biofertilization and biocontrol of pathogens (Backer et al., 2018). Commercialized PGPB strains mainly include the members of Agrobacterium, Azospirillum, Bacillus, Paenibacillus, Pseudomonas, Streptomyces et al. (Lucy, Reed \& Grick, 2004; Banerjee, Yesmin \& Vessey, 2006). PGPB may promote plant growth directly usually by either facilitating resource acquisition (e.g., nitrogen fixation, production of indolic compounds and siderophores, phosphate solubilization, and 1-aminocyclopropane-1-carboxylate deaminase activity) or indirectly by decreasing the inhibitory effects of various pathogenic agents on plant growth and 
52 development (antibiotics and lytic enzymes), that is, by acting as biocontrol bacteria (Glick, 53 2012).

54 Nitrogen $(\mathrm{N})$ fixation is catalyzed by molybdenum-dependent nitrogenase, which is a 55 metalloenzyme composed of two protein components, referred to as MoFe protein and $\mathrm{Fe}$

56

57

58

59

60

61

62

63

64

65

66

67

68

69

70

71

72

73

74

75

76

77

78

79

80

81

82

83

84

85

86

87 protein. The atmospheric $\mathrm{N}_{2}$ is reduced to bioavailable $\mathrm{NH}_{4}{ }^{+}$by nitrogen fixation, providing a large amount of natural $\mathrm{N}$ into cultivated agricultural systems (Galloway et al., 2008). In addition to symbiotic $\mathrm{N}_{2}$-fixing Rhizobia associated with legumes, the non-symbiotic $\mathrm{N}_{2}$-fixing bacteria are also important contributors to the $\mathrm{N}$ nutrition of non-legumes (Gupta, Roper \& Roget, 2006). It is estimated that the microbial $\mathrm{N}$ accounts for roughly $30-50 \%$ of the total $\mathrm{N}$ in crop fields (Liu et al., 2017).

Iron is the fourth most abundant element on earth but its bioavailability is extremely limited due to its poor solubility (Braun \& Braun, 2002; Miethke \& Marahiel, 2007; Kazamia et al., 2018). Microbes have evolved strategies to obtain sufficient amounts of iron, such as chelation, reduction, and protonation (Guerinot, 1994). The use of a siderophore to transport iron by chelation is vitally important for bacteria. Siderophores are low molecular weight compounds (500-1500 Da) possessing a high affinity for $\mathrm{Fe}^{3+}\left(K_{\mathrm{f}}>10^{30}\right)$ (Haas \& Defago, 2005) and they are synthesized by bacteria through non-ribosomal pathways (Hutchins et al., 1999; Khan et al., 2017). Many PGPB have been reported to produce siderophores, such as Bacillus subtilis, Paenibacillus polymyxa SK1, Mesorhizobium sp., Brevibacillus brevis GZDF3 (Franco-Sierra et al., 2020; Khan et al., 2020; Menéndez et al., 2020; Sheng et al., 2020). The chelate of siderophores and ferric iron can be directly absorbed by plants and are called mechanism III, which is thought to be used by plants to resist iron stress (Shenker et al., 1992; Yehuda et al., 1996; Chen, Dick \& Streeter, 2000). When grown under iron-limiting conditions, mung bean plants by inoculation with the siderophore-producing Pseudomonas strain GRP3 showed reduced chlorotic symptoms and an enhanced chlorophyll level compared to uninoculated plants (Sharma et al., 2003). Tomato seedlings inoculation with these two Mesorhizobium strains that produce siderophores and IAA showed significantly higher plant growth traits than uninoculated seedlings (Menéndez et al., 2020). In addition, siderophores secreted by PGPB can suppress plant pathogens by competing for trace amounts of iron in the environment (Glick, 2012). It has been suggested that biocontrol PGPB produce siderophores that have a much greater affinity for iron than do fungal pathogens so that the fungal pathogens are unable to proliferate in the root rhizosphere of the host plant due to lack of iron (Schippers et al., 1987; O'Sullivan \& O'Gara, 1992). For examples, siderophores have biocontrol roles against plant pathogens, such as Pirycularia oryzae (Yuquan et al., 1999), Stagonospora curtisii (Shuangya, Yongxiang \& Xiangqun, 2003), Fusarium oxysporum (Duijff et al., 1993), Macrophomina phaseolina (Arora, Kang \& Maheshwari, 2001) and Cryphonectria parasitica (Chen et al., 2006). 
88

89

90

91

92

93

94

95

96

97

98

99

100

101

102

103

104

105

106

107

108

109

110

111

112

113

114

115

116

117

118

119

120

121

122

Indolic acids include several compounds, of which indole-3-acetic acid (indole acetic acid, IAA) is by far the most common as well as the most studied auxin (Xie et al., 2005). They stimulate cell division and promote cell elongation (Katzy et al., 1990; Weyers \& Paterson, 2001). They are abundant in higher plants and rhizospheric microorganisms and play a vital role in plant-microbe interactions (Beneduzi et al., 2008; Costacurta \& Vanderleyden, 1995; Lambrecht et al., 2000; Beck, Hansen \& Lauritsen, 2003; Mao et al., 2014). Previous studies have demonstrated that Paenibacillus spp. can produce indolic compounds to promote plant growth (Kumari \& Thakur., 2018; Castellano et al., 2018; Lebuhn, Heulin \& Hartmann, 1997). Endophytic bacteria promote growth of the medicinal legume Clitoria ternatea by IAA production, P and K-solubilization (Aeron, Maheshwari \& Meena, 2020).

Paenibacillus triticisoli BJ-18 $\left(=\right.$ DSM $25425^{\mathrm{T}}=$ CGMCC $\left.1.12045^{\mathrm{T}}\right)$ is a $\mathrm{N}_{2}$-fixing bacterium isolated by our laboratory from wheat rhizosphere soil in Beijing (Wang et al., 2013). Recently, we have shown that inoculation with $P$. triticisoli BJ-18 significantly promotes the growth of tomato, maize and wheat (Xie et al., 2016; Shi et al., 2016; Li et al., 2019). The ${ }^{15} \mathrm{~N}$-isotopeenrichment experiment indicated that plant seedlings inoculated with $P$. triticisoli BJ-18 derived $12.9-36.4 \% \mathrm{~N}$ from nitrogen fixation (Li et al., 2019). However, the secondary metabolites of $P$. triticisoli BJ-18 have never been isolated or characterized. In this study, six compounds, composed of three siderophores and three indolic acids, were isolated and characterized from $P$. triticisoli BJ-18. Notably, a new siderophore and a new indolic acid were here identified. Our results will provide insight into the mechanisms by which $P$. triticisoli $\mathrm{BJ}-18$ promotes plantgrowth, including nitrogen fixation and the secretion of siderophores and indolic acids.

\section{Materials \& Methods}

\section{Bacterial strain}

The bacterial strain Paenibacillus triticisoli BJ-18 (=DSM $25425^{\mathrm{T}}=$ CGMCC $\left.1.12045^{\mathrm{T}}\right)$ was used in our study.

\section{Untargeted metabolomics by LC-MS}

The equipment and raw data for untargeted metabolomics were provided by Beijing Novogene Technology Co., Ltd. P. triticisoli BJ-18 was cultured in Lysogeny Broth (LB) (10 g tryptone, 5 g yeast, $10 \mathrm{~g} \mathrm{NaCl}, 15 \mathrm{~g}$ agar per $1 \mathrm{~L} \mathrm{H}_{2} \mathrm{O}$ ) at $30^{\circ} \mathrm{C}$ for 3 days. A single colony was inoculated in $20 \mathrm{~mL} \mathrm{CH}$ medium ( $30 \mathrm{~g}$ sucrose, $6.4 \mathrm{~g}$ tryptone, $7 \mathrm{~g}$ yeast, $0.6 \mathrm{~g} \mathrm{MgSO}_{4} \cdot 7 \mathrm{H}_{2} \mathrm{O}, 3.5 \mathrm{~g} \mathrm{NaCl}, 0.1$ $\mathrm{g} \mathrm{K}_{2} \mathrm{HPO}_{4}, 0.4 \mathrm{~g} \mathrm{KH}_{2} \mathrm{PO}_{4}$ per $1 \mathrm{~L} \mathrm{H}_{2} \mathrm{O}$ ) and cultured at $30{ }^{\circ} \mathrm{C} 200 \mathrm{rpm}$ for $48 \mathrm{~h}$. The seed solution was inoculated into $150 \mathrm{~mL}$ of $\mathrm{CH}$ medium at an inoculation amount of $2 \%$ and cultured at $30{ }^{\circ} \mathrm{C} 200 \mathrm{rpm}$ for 48 hours. Cells were harvested by centrifugation at $6000 \mathrm{rpm}$ at $4{ }^{\circ} \mathrm{C}$ for 10 min, ground with liquid nitrogen, and resuspended with $500 \mu \mathrm{L}$ of $80 \%$ methanol solution containing $0.1 \%$ formic acid. The homogenate was incubated on ice for $5 \mathrm{~min}$ and was 
123 centrifuged at $15000 \mathrm{rpm}$ at $4{ }^{\circ} \mathrm{C}$ for $10 \mathrm{~min} .200 \mu \mathrm{L}$ of supernatant was subsequently transferred 124 to a fresh Eppendorf tube with a $0.22 \mu \mathrm{M}$ filter and was centrifuged at $15000 \mathrm{rpm}$ at $4^{\circ} \mathrm{C}$ for 10 $125 \mathrm{~min}$. LC-MS/MS analyses were performed using the Vanquish UHPLC system (Thermo Fisher) 126 coupled with an Orbitrap Q Exactive series mass spectrometer (Thermo Fisher) in a Hyperil 127 Gold column $(100 \times 2.1 \mathrm{mM}, 1.9 \mu \mathrm{M})$ with a $16-\mathrm{min}$ linear gradient at a flow rate of $0.2 \mathrm{~mL} / \mathrm{min}$. 128 The eluents for the positive polarity mode were eluent A ( $0.1 \%$ formic acid in water) and eluent 129 B (methanol). The eluents for the negative polarity mode were eluent A (5 mM ammonium 130 acetate, $\mathrm{pH}$ 9.0) and eluent $\mathrm{B}$ (methanol). The solvent gradient was set as follows: $2 \% \mathrm{~B}, 1.5 \mathrm{~min}$; $1312-100 \% \mathrm{~B}, 12.0 \mathrm{~min} ; 100 \% \mathrm{~B}, 14.0 \mathrm{~min} ; 100-2 \% \mathrm{~B}, 14.1 \mathrm{~min} ; 2 \% \mathrm{~B}, 16 \mathrm{~min}$. The Q exactive 132 mass series spectrometer was operated in positive/negative polarity mode with spray voltage of $1333.2 \mathrm{kV}$, sheath gas flow rate of $35 \mathrm{arb}$, aux gas flow rate of $10 \mathrm{arb}$, and a capillary temperature of $134320^{\circ} \mathrm{C}$. Compound discoverer 3.0 (CD 3.0, Thermo Fisher) was used for processing the data files 135 to match results from the mzCloud (https://www.mzcloud.org/) and ChemSpider 136 (http://www.chemspider.com/) databases. Accurate qualitative and relative quantitative results 137 were obtained through statistical analysis.

138

139

140

141

142

143

144

145

146

147

148

149

150

151

152

153

154

155

\section{Reagents and instruments for separation and purification of compounds 1-6}

HPLC data were acquired using a Waters 2695 instrument. HRESIMS and HPLC-ESI-MS data were obtained using an Accurate-Mass-Q-TOF LC/MS 6520 instrument (Agilent, USA) in positive ion mode. ${ }^{1} \mathrm{H}$ and ${ }^{13} \mathrm{C}$ NMR data were obtained by Bruker Avance-500 spectrometers (Rheinstetten, Germany) with solvent signals (DMSO- $d_{6}, \delta_{\mathrm{H}} 2.500 / \delta_{\mathrm{C}} 39.520$ ) as references, and HSQC and HMBC experiments were optimized for 145.0 and $8.0 \mathrm{~Hz}$, respectively. The optical rotations measurement was conducted on an Anton Paar MCP200 polarimeter (Anton Paar, Austria). Optical rotations were conducted using a Perkin-Elmer 241 polarimeter, and UV data were detected by a Shimadzu Biospec-1601 spectrophotometer. The absorbance of 96-well clear plate was measured on a microplate reader (Molecular Devices, SpectraMax ${ }^{\circledR}$ Paradigm $^{\circledR}$ ). Analytically pure solvents including methanol, dichloromethane, and ethyl acetate were used for extraction and chromatographic separation. TLC was carried out on silica gel $\mathrm{HSGF}_{254}$ plates and spots were visualized by UV at $254 \mathrm{~nm}$ or sprayed with $10 \% \mathrm{H}_{2} \mathrm{SO}_{4}$ and heated. Silica gel (150-250 $\mu \mathrm{M}$, Qingdao Haiyang Chemical Co., Ltd.), octadecylsilyl (ODS, $50 \mu \mathrm{M}$, YMC CO., LTD), and Sephadex LH-20 (Amersham Biosciences) were used for column chromatography (CC). HPLC separation was performed on an Agilent 1200 HPLC system with a Diode Array Detector (DAD) detector using an ODS column $\left(\mathrm{C}_{18}, 250 \times 9.4 \mathrm{mM}\right.$, YMC Pak, $\left.5 \mu \mathrm{M}\right)$ at a flow rate of $2.0 \mathrm{~mL} / \mathrm{min}$. 
156

157

158

159

160

161

162

163

164

165

166

167

168

169

170

171

172

173

174

175

176

177

178

179

180

181

182

183

184

185

186

187

188

\section{Extraction and isolation of the secondary metabolites}

P. triticisoli BJ-18 was grown in a $500 \mathrm{~L}$ fermenter (Biotech, Shanghai Baoxing Biological Equipment Engineering Co., Ltd.) filled with $200 \mathrm{~L}$ of $\mathrm{CH}$ medium at $\mathrm{pH} 5.0$ with $40 \%$ to $60 \%$ dissolved oxygen and shaking at $100 \mathrm{rpm}$ and at $30{ }^{\circ} \mathrm{C}$ for $48 \mathrm{~h}$. For doing this, this bacterium was inoculated into $20 \mathrm{~mL}$ of $\mathrm{CH}$ medium and then scaled-up to $20 \mathrm{~L}$. The seed culture was inoculated into $200 \mathrm{~L}$ of $\mathrm{CH}$ medium with an inoculation amount of $1 \%$ in a $500 \mathrm{~L}$ fermenter.

The fermented culture was passed through a 200 mesh macroporous adsorption resin following 3 periods of 30-minute ultrasonic cell-breaking and was eluted with analytically pure methanol. The organic solvent was collected and evaporated using rotary evaporators to obtain the crude extract $(7 \mathrm{~g})$. The aqueous phase was discarded after being extracted and separated three times between the ethyl acetate and the aqueous phases, and the organic phase was retained and evaporated using rotary evaporators. The final product was $4 \mathrm{~g}$ of EtOAc (ethyl acetate) extract.

The EtOAc extract was separated into 20 subfractions (Pt-1 to Pt-20) after being subjected to ODS column chromatography with a gradient of methanol-water (5-100\%). The fraction Pt-10 was further partitioned by Sephadex LH-20 CC separated by 50\% methanol in water to create 26 subfractions (Pt-10-1 to Pt-10-26). Compound 4 (4.2 mg, $t_{\mathrm{R}} 31.2 \mathrm{~min}$ ) was obtained from fraction Pt-10-24 (21.3 mg) by RP-HPLC using 55\% methanol in acidic water. Fraction Pt-13 was divided into 16 fractions, Pt-13-1 to Pt-13-16, after being subjected to ODS column chromatography with a gradient of $\mathrm{MeOH}-\mathrm{H}_{2} \mathrm{O}(40-80 \%)$. Compounds 1-3 (2 mg, $3.1 \mathrm{mg}$ and 8 $\mathrm{mg}, t_{\mathrm{R}} 62.5 \mathrm{~min}, 58.4 \mathrm{~min}$ and $37.4 \mathrm{~min}$, respectively) were obtained from fractions Pt-13-6 (42.5 mg) by RP-HPLC using 20\% acetonitrile in acidic water. Fraction Pt-15 was further partitioned by Sephadex LH-20 CC eluted with 90\% methanol in water to cut to 6 subfractions (Pt-15-1 to Pt-15-6). Compound 5 (214 $\mathrm{mg}, t_{\mathrm{R}} 42.5 \mathrm{~min}$ ) was obtained from fraction Pt-15-4 (830 mg) by RP-HPLC using 72\% methanol in acid water. Compound $6\left(37.6 \mathrm{mg}, t_{\mathrm{R}} 62.5 \mathrm{~min}\right)$ was isolated from fraction Pb-17 (928 mg) by RP-HPLC (C8) using 80\% methanol in acid water.

Deshydroxylferritriacetylfusigen (compound 1): yellow powder; $[\alpha]^{25}=-14.0(c \quad 0.10$, $\mathrm{MeOH}) ; \mathrm{UV}(\mathrm{MeOH}) \lambda_{\max }(\log \varepsilon) 214(2.44) \mathrm{nm}$; NMR data $\left(500 \mathrm{MHz}, \mathrm{DMSO}-d_{6}\right)$ is shown in Table 1; positive HRESIMS $m / z$ 837.4242 $[\mathrm{M}+\mathrm{H}]^{+}$(calculated for $\mathrm{C}_{39} \mathrm{H}_{61} \mathrm{~N}_{6} \mathrm{O}_{14}, 837.4246$ $\Delta=0.0004)$.

Desferritriacetylfusigen (compound 2): yellow powder; $[\alpha]^{25}=-8.0(c \quad 0.05, \mathrm{MeOH}) ; \mathrm{UV}$ $(\mathrm{MeOH}) \lambda_{\max }(\log \varepsilon)=214(2.43) \mathrm{nm}$; positive HRESIMS $m / z 853.4203[\mathrm{M}+\mathrm{H}]^{+}$, (calculated for $\left.\mathrm{C}_{39} \mathrm{H}_{60} \mathrm{~N}_{6} \mathrm{O}_{15}, 853.4195 \Delta=0.0008\right)$. 
189

190

191

192

193

194

195

196

197

198

199

200

201

202

203

204

205

206

207

208

209

210

211

212

213

214

215

216

217

218

219

220

221

222

Triacetylfusigen (compound 3): brown powder; $[\alpha]^{25} \mathrm{D}=-216.0(c \quad 0.025, \mathrm{MeOH}) ; \mathrm{UV}$ $(\mathrm{MeOH}) \lambda_{\max }(\log \varepsilon) 211(2.35) \mathrm{nm}$; positive HRESIMS $m / z 906.3316[\mathrm{M}+\mathrm{H}]^{+}$(calculated for $\left.\mathrm{C}_{39} \mathrm{H}_{58} \mathrm{~N}_{6} \mathrm{O}_{15} \mathrm{Fe}, 906.3309 \Delta=0.0007\right)$.

Paenibacillic acid A (compound 4): white powder; $[\alpha]^{25}=-39.99(c 0.10, \mathrm{MeOH})$; UV $(\mathrm{MeOH}) \lambda_{\max }(\log \varepsilon) 211$ (2.33) nm; NMR data $\left(500 \mathrm{MHz}, \mathrm{DMSO}-d_{6}\right)$ is shown in Table 2; positive HRESIMS $m / z 303.1704[\mathrm{M}+\mathrm{H}]^{+}$(calculated for $\mathrm{C}_{17} \mathrm{H}_{23} \mathrm{~N}_{2} \mathrm{O}_{3} 303.1708 \Delta=0.0004$ ).

3-Indoleacetic acid (IAA) (compound 5): white amorphous powder; UV (MeOH) $\lambda_{\max }(\log \varepsilon)$ 234 (4.22), 272 (3.77), 280 (3.80), 290 (3.72) nm; positive HRESIMS m/z 176.0709 [M + H] ${ }^{+}$ (calculated for $\mathrm{C}_{10} \mathrm{H}_{10} \mathrm{NO}_{2} 176.0701 \Delta=0.0008$ ).

3-Indolepropionic acid (IPA) (compound 6): white amorphous powder; UV $(\mathrm{MeOH}) \lambda_{\max }(\log$ ع) 235(4.25), 270 (3.77), 280 (3.80), 290 (3.72) nm; positive HRESIMS $m / z$ 190.0871 [M + H $]^{+}$ (calculated for $\mathrm{C}_{11} \mathrm{H}_{12} \mathrm{NO}_{2}, 190.0868 \Delta=0.0003$ ).

\section{Conversion of compound 3 into desferritriacetylfusigen}

The removal of the ferric ion was conducted as reported by Kodani et al. (2015) with additional changes. Compound $3(4 \mathrm{mg})$ was dissolved in $1.5 \mathrm{~mL}$ of water and then $1.5 \mathrm{~mL}$ of $1 \mathrm{M}$ 8-quinolinol was added. The solution was stirred for $25 \mathrm{~min}$ and mixed with $3 \mathrm{~mL}$ of $\mathrm{CH}_{2} \mathrm{Cl}_{2}$, then left to stand until bilayer separation occurred. The water layer was evaporated using a freeze-dryer vacuum. This was repeated 3 times to eliminate ferri-8-quinolinol and obtain the total dry material. The sample was then dissolved in $100 \mu \mathrm{L}$ of methanol and HPLC purification was performed with the $\mathrm{C} 18$ column $(7.8 \times 300 \mathrm{mM}$, Waters, $7 \mu \mathrm{M}$; detector: UV), eluted with $20 \%$ acetonitrile in water at a flow rate of $1 \mathrm{~mL} / \mathrm{min}$, and monitored at $\mathrm{OD}_{210}$ to create $2.0 \mathrm{mg}$ of desferri-compound 3. Positive HRESIMS and NMR of desferri-compound 3 was the same as compound 2.

\section{Computations}

Systematic conformational searches of structure 4a were carried out using MMFF94 force field and CONFLEX (Liu et al., 2018).

\section{Determination of plant growth promoting capacity of indolic compounds}

The seeds of Arabidopsis thaliana var. Columbia were sterilized using 75\% ethanol for 45 seconds, $5 \% \mathrm{NaClO}$ for 15 minutes, and were washed in sterile water 3 times. The seeds were then placed horizontally on solid 1/2 Murashige and Skoog (MS) (Murashige \& Skoog, 1962) medium supplemented with $1.5 \%$ sucrose, $0.35 \%(\mathrm{w} / \mathrm{v})$ agar, and different concentrations and combinations of $1 \mathrm{mg} / \mathrm{L}$ paenibacillic acid A, IAA, and IPA for direct regeneration. At least ten Arabidopsis strains were cultured in each group of treatments. The cultures were incubated at 25 $\pm 2{ }^{\circ} \mathrm{C}$ under cool fluorescent light (2000 lux $16 \mathrm{~h}$ /day photoperiod) for 14 days. The ability of 
223 the three indolic acids to promote plant growth was evaluated by measuring the dry weight of the 224 stems and roots of Arabidopsis thaliana.

\section{Detection of indolic compounds}

226

227

228

229

230

231

232

233

234

235

236

237

238

239

240

241

242

243

244

245

246

247

248

249

250

251

252

253

254

The Salkowski Reagent (PC technique) was used to determine concentrations of indolic compounds (Glickmann \& Dessaux, 1995). IAA standard solutions with concentrations of 0, 5.0, $10.0,15.0,20.0$, and $25.0 \mu \mathrm{g} / \mathrm{mL}$ were used to react with an equal volume of PC reagent in the dark for half an hour and the $\mathrm{OD}_{530}$ value was measured to draw the Salkowski calibration curve. The $\mathrm{R}^{2}$ value should be greater than 0.99 .

P. triticisoli BJ-18 was grown overnight in $50 \mathrm{~mL}$ of $\mathrm{LB}$ medium at $200 \mathrm{rpm} 30^{\circ} \mathrm{C}$. The cells were collected by centrifugation, washed three times with deionized water, and resuspended in 1 $\mathrm{mL}$ of deionized water. $100 \mu \mathrm{L}$ of the bacterial suspension was added to $20 \mathrm{~mL}$ nitrogendeficient medium (prepared with deionized water and supplemented with $100 \mathrm{mM} \mathrm{NH}_{4} \mathrm{Cl}$ as a nitrogen source) with $36 \mathrm{mg} / \mathrm{L}$ iron citrate or no iron citrate. After three days of incubation at 200 $\mathrm{rpm}$ and $30^{\circ} \mathrm{C}$, all samples were treated with the same method to measure the corresponding $\mathrm{OD}_{530}$ value. The content of indolic compounds of each sample was calculated using the Salkowski calibration curve. The nitrogen-deficient medium with deionized water was used as a blank control. Each sample was treated three times.

\section{Antimicrobial assay}

The antimicrobial assay was performed according to the recommended guidelines of the National Center for Clinical Laboratory Standards (NCCLS) (Li et al., 2008). The bacterial cells of Escherichia coli (ATCC1.0090), Staphylococcus aureus (ATCC6538), and Bacillus subtilis (ATCC6663) were grown in Mueller-Hinton Broth (MHB) medium (5.0 g beef powder, $1.5 \mathrm{~g}$ starch, $17.5 \mathrm{~g}$ acid hydrolyzed casein, and $1 \mathrm{~L} \mathrm{H}_{2} \mathrm{O}$ ) at $37{ }^{\circ} \mathrm{C}$ for $24 \mathrm{~h}$. The fungus (yeast), Candida albicans (CGMCC2.2086), was grown in Saurer's Dextrose Broth (SDB) medium (5 g casein trypsin digest, $5 \mathrm{~g}$ gastric enzyme digest, $20 \mathrm{~g}$ dextrose and $1 \mathrm{~L} \mathrm{ddH}_{2} \mathrm{O}$ ) at $28^{\circ} \mathrm{C}$ for $48 \mathrm{~h}$.

The cells of bacteria and yeast cultivated in MHB and SDB media as described above were seeded onto each well of a 96-well clear plate, then the gradient concentrations of test compounds 1-6 were added to each well and mixed with the targeted microbes to reach a final volume of $100 \mu \mathrm{L}$. The inoculation concentrations of bacteria and yeast were $0.5-2.5 \times 10^{5} \mathrm{cfu} /$ $\mathrm{mL}$ and $0.5-2.5 \times 10^{3} \mathrm{cfu} / \mathrm{mL}$, respectively. The suspension was cultured at $37^{\circ} \mathrm{C}$ for 1 day and $28^{\circ} \mathrm{C}$ for 2 days, respectively. Gentamicin, ampicillin, sulphate streptomycin, and amphotericin $\mathrm{B}$ were used as positive controls. A microplate reader was employed to perform at the $\mathrm{OD}_{595}$. 
255 The $\mathrm{IC}_{50}$ of compounds 1-6 were plotted, calculated, and obtained. Each antimicrobial assay was 256 tested in triplicate.

\section{Siderophores detection by blue agar CAS assay}

258 Siderophores were detected using a blue agar CAS medium as described by Schwyn and

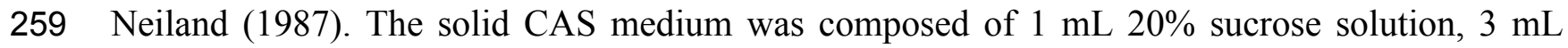
260 sterilized $10 \%$ casamino acid, $100 \mu \mathrm{L} 1 \mathrm{mmol} / \mathrm{L} \mathrm{CaCl}_{2}, 5 \mathrm{~mL}$ CAS dye solution (a mixture of $2610.012 \mathrm{~g}$ of chrome azurol $\mathrm{S}$ in $10 \mathrm{~mL}$ of $\mathrm{ddH}_{2} \mathrm{O}, 2 \mathrm{~mL} 1 \mathrm{mmol} / \mathrm{L} \mathrm{FeCl}_{3}$, and $0.015 \mathrm{~g}$ 262 hexadecyltrimethylammonium bromide in $8 \mathrm{~mL}$ of deionized $\mathrm{H}_{2} \mathrm{O}$ ), PIPES buffer $(\mathrm{pH}$ 6.8-7.0), 263 and $2 \mathrm{~g}$ agar powder per $100 \mathrm{~mL} \mathrm{H}_{2} \mathrm{O}$.

P. triticisoli BJ-18 was inoculated in $20 \mathrm{~mL}$ of liquid LB medium with shaking at $200 \mathrm{rpm}$ at 265 $30{ }^{\circ} \mathrm{C}$ for $48 \mathrm{~h}$. $1 \mathrm{~mL}$ of the bacterial solution was centrifuged, washed with sterile deionized water, and then suspended with $200 \mu \mathrm{L}$ of sterile deionized $\mathrm{H}_{2} \mathrm{O} .10 \mu \mathrm{L}$ of the suspension was 268 inoculated on a CAS plate. The color changed from blue to light orange, indicating the presence of iron carriers.

\section{Results}

\section{Untargeted metabolomics profiling of $P$. triticisoli BJ-18}

271

The untargeted metabolomics profiling of $P$. triticisoli BJ-18 were analyzed by using LC-MS

272 and the data were comparatively analyzed with the databases of mzCloud, ChemSpider and mzVault. A total of 101 compounds were measured, the majority of which were common compounds involved in the basic metabolism (Table S1), including carbohydrates, amino acids, peptides, alcohols, aldehydes, ketones, fatty acids, lipids, nucleic acids, vitamins, alkaloids, cyclics and their respective derivatives (Fig 1A). Of the 101 compounds, 46 have the molecular weights of 100-200 Da, 34 have the molecular weights of 200-300 Da, 18 have the molecular weights of more than $300 \mathrm{Da}$ and 3 have the molecular weights of less than $100 \mathrm{Da}$ (Fig. 1B).

Notably, $\mathrm{N}^{2}$-acetyl ornithine, a precursor to fusarinines, is included among these compounds. Also, plant growth regulators such as trehalose 6-phosphate (T6P, resistant to drought and salt stress. Wingler et al., 2012; Prasad et al., 2014; Kretzschmar et al., 2015), betaine (a non-toxic osmotic regulator. Cho et al., 2003; Tramontano \& Jouve, 1997) and trigonelline (resistant to salt stress. Minorsky, 2002; Tramontano \& Jouve, 1997), and other active molecules such as oxymatrine (a drug used to treat hepatitis B and tumors. Lu et al., 2003; Song et al., 2006), 
285

286

287

288

289

290

291

292

293

294

295

296

297

298

299

300

301

302

303

304

305

306

307

308

309

310

311

312

313

314

315

316

317

318

319

diosmetin (in food or medicine with anti-oxidant properties, anti-infective, and anti-shock functions. Pallab et al., 2019), luotonin A (anti-tumor drug. González-Ruiz et al., 2010), $\alpha-$ humulene (hippone, sesquiterpene, with anti-inflammatory effect. Rogerio et al., 2009), (-)caryophyllene oxide (anti-tumor and antifungal drug. Yang et al., 1999; Park et al., 2011), tetrahydrocurcumin (hepatotoxicity prevention drug and natural whitening ingredients. Pari \& Murugan, 2004; Trivedi et al., 2017) were also included among these compounds.

\section{Structural determination of secondary metabolites from P. triticisoli BJ-18}

The cells of P. triticisoli BJ-18 were fermented and concentrated, and $4 \mathrm{~g}$ of EtOAc extracts was obtained. The extracts were separated using a combination of silica gel chromatography, sephadex LH-20, ODS column chromatography, and HPLC. Six compounds (compounds 1-6) were ultimately obtained and were further analyzed using NMR and MS to establish their structures. Further the structure and characters of the six compounds (compounds 1-6) were compared with the corresponding compounds in the literature. Among the six compounds, compounds 1-3 were identified as fusarinines that were classical siderophores, while compounds 4-6 were identified as indolic acids (Fig. 2). Both compound $\mathbf{1}$ and $\mathbf{4}$ have new structures.

Compound 2 was a cyclic tripolymer which has three same monomers $(\mathrm{m} / \mathrm{z} 284.1366)$ identified as desferritriacetylfusigen (Anke, 1977). It was characterized by ${ }^{1} \mathrm{H}$ NMR $(500 \mathrm{MHz}$, DMSO- $\left.d_{6}\right), \delta_{\mathrm{H}} 9.70(\mathrm{~s}), 8.21(\mathrm{~d}, J=7.5 \mathrm{~Hz}), 6.32(\mathrm{~s}), 4.30-4.03(\mathrm{~m}, 3 \mathrm{H}), 3.33(\mathrm{~s}), 2.81(\mathrm{~m})$, $1.88(\mathrm{~s}), 1.85(\mathrm{~s}), 1.75-1.39(\mathrm{~m}, 4 \mathrm{H})$ (Fig. S1) and by ${ }^{13} \mathrm{C}$ NMR (125 MHz, DMSO- $\left.d_{6}\right) \delta_{\mathrm{C}} 22.7$, 23.5, 25.8, 28.5, 32.4, 46.8, 52.3, 63.5, 117.9, 150.1, 167.4, 170.0, 172.6 (Fig. S2). Compound 5 was identified as 3-indoleacetic acid (IAA) (Gathungu et al., 2014). As shown in Fig. S3, it was characterized by ${ }^{1} \mathrm{H}$ NMR $\left(500 \mathrm{MHz}, \mathrm{DMSO}-d_{6}\right), \delta_{\mathrm{H}} 12.14$ (s), $10.90(\mathrm{~s}), 7.49$ (d, $J=7.9 \mathrm{~Hz}$ ), $7.34(\mathrm{~d}, J=8.1 \mathrm{~Hz}), 7.22(\mathrm{~d}, J=2.3 \mathrm{~Hz}), 7.07(\mathrm{t}, J=7.6 \mathrm{~Hz}), 6.98(\mathrm{t}, J=7.4 \mathrm{~Hz}), 3.63(\mathrm{~s}, 2 \mathrm{H})$. Compound 6 was identified as 3-indolepropionic acid (IPA) (Rustamova et al., 2019). As shown in Fig. S4, it was characterized by ${ }^{1} \mathrm{H}$ NMR $\left(500 \mathrm{MHz}\right.$, acetone- $\left.d_{6}\right), \delta_{\mathrm{H}} 9.97(\mathrm{~s}), 7.59$ (d, $J=7.9$ $\mathrm{Hz}), 7.37(\mathrm{~d}, J=8.1 \mathrm{~Hz}), 7.16(\mathrm{~s}), 7.09(\mathrm{t}, J=7.5 \mathrm{~Hz}), 7.02(\mathrm{t}, J=7.5 \mathrm{~Hz}), 3.06(\mathrm{t}, J=7.7 \mathrm{~Hz})$, $2.70(\mathrm{t}, J=7.7 \mathrm{~Hz})$.

Compound 1 was a new member of fusarinines (siderophores) and compound 4 was a new member of the indolic acids. Their structures were further determined by extensive spectroscopic experiments. The structure of compound $\mathbf{3}$ was determined by NMR after iron was removed and it was identified as triacetylfusigen. Overall, the six compounds include three fusarinines (siderophores) and three indolic acids. (Fig. 2).

Compounds $\mathbf{1}, \mathbf{3}$, and $\mathbf{4}$, are described in greater detail as follows:

Deshydroxylferritriacetylfusigen (compound 1) was a yellow powder with a molecular formula of $\mathrm{C}_{39} \mathrm{H}_{60} \mathrm{~N}_{6} \mathrm{O}_{14}$ (thirteen degrees of unsaturation) by HRESIMS $m / z 837.4242[\mathrm{M}+\mathrm{H}]^{+}$ 
320 (calculated for $\mathrm{C}_{39} \mathrm{H}_{61} \mathrm{~N}_{6} \mathrm{O}_{14}, 837.4246$ ). Its ${ }^{1} \mathrm{H},{ }^{13} \mathrm{C}$ and HSQC NMR spectroscopic data (Figs. 321 S5, S6 \& S7) suggested the existence of two methyl groups ( $\delta_{\mathrm{C} / \mathrm{H}} 22.3 / 1.84$ and $\left.25.3 / 1.87\right)$, five 322 methylenes, including one $O$-methylene $\left(\delta_{\mathrm{C} / \mathrm{H}} 63.1 / 4.17\right.$ and 4.12$)$, one double bond $\left(\delta_{\mathrm{C} / \mathrm{H}}\right.$ $323117.5 / 6.31$ and $\left.\delta_{\mathrm{C}} 149.6\right)$, three carboxylic carbons $\left(\delta_{\mathrm{C}} 166.0,169.5\right.$ and 172.1), one $N$-methine $324\left(\delta_{\mathrm{C} / \mathrm{H}} 51.8 / 4.19\right)$, one amide $N-\mathrm{H}$ proton $\left(\delta_{\mathrm{H}} 8.23\right)$, and one amide $\mathrm{N}-\mathrm{OH}$ proton $\left(\delta_{\mathrm{H}} 9.92\right)$. 325 Thirteen carbon signals in the ${ }^{13} \mathrm{C}$ NMR and thirty-nine in the molecular formula indicated that 326 compound 1 was a cyclic tripolymer similar to compound 2. Comparison of MS-MS spectrum of

327

328

329

330

331

332

333

334

335

336

337

338

339

340

341

342

343

344

345

346

347

348

349

350

351

352

353

354

355 compound 1 (Fig. S8) and compound 2 (Fig. S9) revealed that unlike compound 2, two of the three monomers of compound $\mathbf{1}$ have the same molecular weight as the monomers of compound $2(\mathrm{~m} / \mathrm{z} 284.1366)$, and the other was different $(\mathrm{m} / \mathrm{z} 268.1566)$. The molecular weight of this unique monomer is 16 less than that of others, which is the molecular weight of an oxygen atom. Although the NMR of compound 1 was similar to compound 2, the integration of N-OH protons in ${ }^{1} \mathrm{H}$ NMR of compound $\mathbf{1}$ was less than compound $\mathbf{2}$. The molecular formula also suggested that there were only two hydroxyls in compound $\mathbf{1}$ rather than three. The planar structure was confirmed by combining ${ }^{1} \mathrm{H}-{ }^{1} \mathrm{H}$ COSY and HMBC (Figs. S10 \& S11 Fig. 3). The ROESY spectrum (Fig. S12) showed that $\mathrm{CH}_{3}-11$ had the NOE correlation with the olefinic proton $\left(\delta_{\mathrm{H}}\right.$ 6.31) indicating that the double bond was in a Z-configuration. Compound $\mathbf{2}$ was deduced to come from ornithine (Schrettl et al., 2007), and the absolute configuration of compound 1 was determined to be $5 S$. Our data suggested that compound $\mathbf{1}$ has a new structure and we proposed the name deshydroxylferritriacetylfusigen for the new number of fusarinines (Table 1) .

Compound 3 was a brown powder with a molecular formula of $\mathrm{C}_{39} \mathrm{H}_{57} \mathrm{~N}_{6} \mathrm{O}_{15} \mathrm{Fe}$ by HRESIMS $\left([\mathrm{M}+\mathrm{H}]^{+}\right.$at $m / z$ 906.3316, calculated for $\left.\mathrm{C}_{39} \mathrm{H}_{58} \mathrm{~N}_{6} \mathrm{O}_{15} \mathrm{Fe}, 906.3309\right)$. Compound 3 had no signal of NMR (Fig. S13) due to its metal-shielding characteristics. A strong complexing agent (Kodani et al., 2015) desferri-compound 3 was a yellow powder with a molecular formula of $\mathrm{C}_{39} \mathrm{H}_{60} \mathrm{~N}_{6} \mathrm{O}_{15}$ (thirteen degrees of unsaturation) by HRESIMS $\left([\mathrm{M}+\mathrm{H}]^{+}\right.$at $m / z$ 853.4203, calculated for $\left.\mathrm{C}_{39} \mathrm{H}_{60} \mathrm{~N}_{6} \mathrm{O}_{15}, 853.4195\right)$ obtained following the precipitation and separation of the metal ions by 8-quinolinol. Analysis of its HRESIMS and ${ }^{1} \mathrm{H}$ NMR (Fig. S14) data revealed that desferricompound $\mathbf{3}$ had the same structure as compound $\mathbf{2}$. Compound $\mathbf{3}$ was determined to be a ferricomplex compound, identified as triacetylfusigen.

Compound 4 was isolated as white amorphous powder with the molecular formula of $\mathrm{C}_{17} \mathrm{H}_{22} \mathrm{~N}_{2} \mathrm{O}_{3}$ (eight degrees of unsaturation) determined by HRESIMS $m / z 303.1704[\mathrm{M}+\mathrm{H}]^{+}$ (calculated for $\mathrm{C}_{17} \mathrm{H}_{23} \mathrm{~N}_{2} \mathrm{O}_{3} 303.1708$ ). The ${ }^{1} \mathrm{H}$ and ${ }^{13} \mathrm{C}$ NMR combining with HSQC (Figs. S15, $\mathrm{S} 16 \& \mathrm{~S} 17)$ revealed one methyl group $\left[\delta_{\mathrm{C} / \mathrm{H}} 13.6 / 0.78(\mathrm{t}, J=7.4 \mathrm{~Hz})\right]$, six methylenes, including two $O$-methylene $\left[\delta_{\mathrm{C} / \mathrm{H}} 67.1 / 3.30(\mathrm{~m})\right.$ and $\left.72.3 / 5.46(\mathrm{~s})\right]$, one ethane $\left[\delta_{\mathrm{C}} 56.1 / 3.63(\mathrm{dd}, J=10.3\right.$, 5.0)], eight aromatic/olefinic carbons $\left(\delta_{\mathrm{C}} 108.2,109.8,118.1,119.7,121.9,126.2,129.4\right.$ and 137.2) and one carboxylic carbons $\left(\delta_{\mathrm{C}} 170.0\right)$. These data suggested that compound 4 was similar

Peer] reviewing PDF | (2019:10:42693:2:0:NEW 24 May 2020) 
356

357

358

359

360

361

362

363

364

365

366

367

368

369

370

371

372

373

374

375

376

377

378

379

380

381

382

383

384

385

386

387

388

to lycoperodine-1 (Yahara et al., 2004). The ${ }^{1} \mathrm{H}-{ }^{1} \mathrm{H}$ COSY data (Fig. S18) revealed four isolated proton spin-systems of C-1-N-C-3-C-4, C-5-C-6, C-7-C-8, and C-3'-C-4'-C-5'-C-6', respectively. The HMBC spectrum (Fig. S19) showed correlations from H-2' to C-3', C-8a and C-9a, from H-1 to C-3 and C-9a, from H-3 and H-4 to C-1, from H-4 to C-9a and C-4a, from H-5 to $\mathrm{C}-5 \mathrm{a}$ and $\mathrm{C}-4 \mathrm{a}$, and from $\mathrm{H}-7$ and $\mathrm{H}-8$ to $\mathrm{C}-8 \mathrm{a}$. The planar structure of compound 4 was established by linking these fragments (Fig. 3 \& Table 2). The ECD calculation method (Ma et al., 2014) was used to determine the absolute configurations. The structure of compound 4 was simplified into two stereoisomers $4 \mathbf{a}(3 S)$ and $\mathbf{4 b}(3 R)$. The calculated ECD curve of compound 4a correlated with the experimental CD spectrum of 4 (Fig. 4). The absolute configuration of compound 4 was established as $3 S$ using the time-dependent density functional theory (TDDFT) at the B3LYP/6-311G $(\mathrm{d}, \mathrm{p})$ level (Fig. S20). Compound $\mathbf{4}$ was the derivative of IPA (here named paenibacillic acid A).

\section{Effects of indolic acids compounds on plant growth promotion}

The effects of indolic acids compounds on growth of Arabidopsis thaliana var. Columbia were investigated. Paenibacillic acid A, IAA, and IPA were shown to promote the growth of plant shoots and roots (Fig. 5) as well as the dry weight of the plants (Fig. 6). The growth-promoting ability increased as the concentration of paenibacillic acid A, IAA, and IPA increased until their highest growth-promoting ability was attained, and then their plant growth-promoting ability decreased with increasing concentration. The significant efficiencies of plant-growth promotion were obtained when the concentrations of paenibacillic acid A, IAA and IPA were at $100 \mathrm{nM}$, $250 \mathrm{nM}$ and $50 \mathrm{nM}$, respectively, suggesting that IPA has the strongest ability of plant growth promotion among the three indolic acids compounds.

We further determined the content of indolic compounds produced by P. triticisoli BJ-18 when it was measured in the nitrogen-deficient medium with and without iron. The results showed that $P$. triticisoli BJ-18 produced $37.03 \pm 1.21 \mu \mathrm{g} / \mathrm{mL}$ of the indolic compounds in a medium with an iron ion concentration of $4.409 \times 10^{-4} \mathrm{mM}$ and $13.457 \pm 0.78 \mu \mathrm{g} / \mathrm{mL}$ of the indolic compounds in a medium without iron, suggesting that the content of indolic compounds in P. triticisoli $\mathrm{BJ}-18$ is positively related to the iron in the environment.

\section{Antimicrobial activity}

The antimicrobial properties of siderophores and indolic acids were assayed against the indicator strains (bacteria E. coli, S. aureus and B. subtilis, and yeast C. albicans) (Table 3). Both compounds 1 and 2 that are siderophores showed antimicrobial activity against E. coli, S. aureus and $B$. subtilis, but did not show obvious inhibitory activity against yeast $C$. albicans. 
389 Gentamicin, ampicillin, streptomycin sulfate and amphotericin B were used as positive controls

390 against E. coli, S. aureus, B. subtilis and C. albicans, respectively. The compounds were tested at 391 concentrations of $5 \mu \mathrm{M}, 10 \mu \mathrm{M}$ and $20 \mu \mathrm{M}$. The $\mathrm{IC}_{50}$ was calculated using the Spearman-

392 Karber's method.

393 Siderophore detection by blue agar CAS assay

394 Siderophore production by $P$. triticisoli BJ-18 was determined by blue agar CAS assay as 395 described in materials and methods. A yellow ring appeared around each colony after seven days 396 of $P$. triticisoli BJ-18 growth on a blue agar plate, indicating that $P$. triticisoli $\mathrm{BJ}-18$ had the 397 ability to secrete siderophores and transfer iron from the environment to the bacterial cells (Fig. 398 S21). The data are consistent with the above results that compounds 1-3 are siderophores.

\section{Discussion}

400

401

402

403

404

405

406

407

408

409

410

411

412

413

414

415

416

417

418

419

420

421

P. triticisoli $\mathrm{BJ}-18$, a $\mathrm{N}_{2}$-fixing bacterium, significantly promoted plant growth, but the secondary metabolites produced by this bacterium have never been characterized. In this study, 101 known compounds of $P$. triticisoli BJ-18 were measured by untargeted metabolomics profiling. These compounds include $\mathrm{N}^{2}$-acetyl ornithine, which is the precursor of fusarinines (siderophores). There are 7 types of siderophores: fusarinines, rhodotorulic acids, ferrichromes, ferrioxamines, aerobactins, enterobactins, and mycobactins (Hossain et al., 1980). Fusarinines are synthesized by aminoacyl bonds, making them different from other types of siderophores that are polymerized using peptide linkages. Fusigen, a cyclic trimester of fusarinine, was identified by Diekmann (Diekmann \& Zähner, 1967) and was considered to be the iron ionophore for Fusarium roseum (Sayer \& Emery, 1968). Studies have shown triacetylfusigen, which has three acetyl group in place of the $\mathrm{H}$ atoms of the amino, was isolated from Aspergillus fumigates (Diekmann \& Krezdorn, 1975) and Aspergillus nidulans (Charlang et al., 1981), while desferritriacetylfusigen was found in Aspergillus deflectus (Anke, 1977) and Emericella sp. (Cruz et al., 2012). These siderophores were isolated from fungi but bacterial fusarinines have never been identified before our study. Here, three fusarinines were isolated from $P$. triticisoli BJ-18 and identified as deshydroxylferritriacetylfusigen, desferritriacetylfusigen, and triacetylfusigen, of which deshydroxylferritriacetylfusigen was a new structure of fusarinine. Here is the first study to report the bacterial fusarinine. Ornithine is the only amino acid of fusarinine (Charlang et al., 1982). The Kyoto Encyclopedia of Genes and Genomes (KEGG, https://www.kegg.jp/) shows that fusarinine can be synthesized by some specific ornithylesterases including fusarinine-C ornithineesterase, ornithine esterase and 5-Nacyl-L-ornithine-ester hydrolase. Studies on fusarinine in fungi have shown that the specific 
422

423

424

425

426

427

428

429

430

431

432

433

434

435

436

437

438

439

440

441

442

443

444

445

446

447

448

449

450

451

452

453

454

455

456

ornithylesterases promote cellular iron-exchange by hydrolysis of the ester bonds of the ferric ionophores (Emery, 1976).

Indolic compounds are natural auxins in plants and rhizosphere microorganisms and can promote the formation of shoot tips, buds, and roots. The auxins commonly used in agriculture are IAA, indolebutyric acid, 2,4-dichlorophenoxyacetic acid and naphthylacetic acid. Three indolic acids identified as paenibacillic acid A, IAA, and IPA were isolated from P. triticisoli BJ18, of which paenibacillic acid A was a new structure. The results of the plant growth promoting capacity assay showed that the three compounds can promote the growth of the shoots and roots of $A$. thaliana and can increase the dry weight of the plant. The effect of paenibacillic acid A on A. thaliana is similar to that of IAA. IPA was the best promoter of plant growth among the three indolic compounds. Indolic compounds such as indole, skatole, and indirubin were concurrently identified by untargeted metabolomics profiling. Our results showed that $P$. triticisoli BJ-18 can promote plant growth by synthesizing plant growth hormones, including indolic acids.

Indolic compounds were usually synthesized in two pathways, either by iron (III) complexed by the ligand of indolic compounds or by the reduction of the soluble iron (II) complex. These parallel reactions cannot proceed without iron (Gazaryan et al., 1996; Kovács et al., 2008; Xie et al., 2016). Indolic acid assays showed that the content of indolic compounds of $P$. triticisoli BJ18 was related to the presence or absence of iron ions. The content of indolic compounds of $P$. triticisoli BJ-18 can reach $37.03 \pm 1.21 \mu \mathrm{g} / \mathrm{mL}$ in the medium with an iron ion concentration of $4.409 \times 10^{-4} \mathrm{mM}$, while the content is $13.457 \pm 0.78 \mu \mathrm{g} / \mathrm{mL}$ in the iron-free environment, indicating the importance of iron for the synthesis of indolic compounds.

Phytopathogens must sequester iron to develop and sustain infections (Ratledge \& Dover, 2000). Competing for iron is a mechanism taken by PGPR to inhibit the growth of phytopathogens in the soil (Chet et al., 1990). The six compounds were evaluated for their activities against a panel of microbes. Results showed that desferritriacetylfusigen and deshydroxylferritriacetylfusigen were antimicrobial against E. coli, S. aureus, and B. subtilis. Triacetylfusigen showed no antibiosis activity against any targeted microorganism due to its complexion with iron.

Plant growth regulators such as betaine and trigonelline, and other active molecules such as luotonin A, aphidicolin, oxymatrine, diosmetin, pilocarpine and tetrahydrocurcumin were also identified by untargeted metabolomics profiling. Besides, deshydroxylferritriacetylfusigen had weak cyotoxic activity against $\mathrm{AsPC}-1$ with $\mathrm{IC}_{50}$ value of $81.2 \pm 3.9 \mu \mathrm{M}$ (supplemental file 1 ), indicating that siderophores may have potential as a new therapy for human cancers (Kalinowski \& Richardson, 2005; Ji, Juarez-Hernandez \& Miller, 2012). The chemical composition and application of $P$. triticisoli BJ-18 is far more complicated and promising. 
457

458

459

460

461

462

463

464

465

466

467

468

469

470

471

472

473

474

475

476

477

478

479

480

481

482

483

484

485

486

487

488

P. triticisoli BJ-18 has been shown to promote plant growth using several mechanisms (Fig. 7). P. triticisoli BJ-18 provides a nitrogen source for plant growth by $\mathrm{N}_{2}$-fixation, produces indolic acids to promote plant growth, generates siderophores to capture iron atoms to synthesize nitrogenase and indolic acids, and synthesizes plant growth regulators such as T6P, betaine and trigonelline, and secretes fusarinines and paenibacillic acid A to resist phytopathogens.

Our results provide chemical evidence for the use of $P$. triticisoli BJ-18 as a PGPR biofertilizer in agriculture. The discovery of the many compounds identified in our study shows the agricultural and medical value of $P$. triticisoli BJ-18. The metabolic regulation of fusarinines and other bioactive compounds requires further study.

\section{Conclusions}

In this study, six compounds were isolated and characterized from $P$. triticisoli BJ-18, a $\mathrm{N}_{2-}$ fixer. The six compounds included three classical siderophore fusarinines identified as deshydroxylferritriacetylfusigen, desferritriacetylfusigen, and triacetylfusigen, and three indolic acids identified as paenibacillic acid A, 3-indoleacetic acid (IAA), and 3-indolepropionic acid (IPA). Both deshydroxylferritriacetylfusigen and paenibacillic acid A have new structures. Fusarinines, which normally occur in fungi, were isolated from bacteria for the first time in this study. Both siderophores (compounds 1 and 2) showed antimicrobial activity against E. coli, $S$. aureus and $B$. subtilis, but did not show obvious inhibitory activity against yeast Candida albicans. Whereas triacetylfusigen (compound 3 ) showed no antibiosis activity against these test microorganisms. Paenibacillic acid A, IAA, and IPA were shown to promote the growth of plant shoots and roots, and paenibacillic acid A also showed antimicrobial activity against $S$. aureus. Our study demonstrated that siderophores and indolic acids may play an important role in plant growth promotion by $P$. triticisoli BJ-18.

\section{References}

Aeron A, Maheshwari DK, Meena VS. 2020. Endophytic bacteria promote growth of the medicinal legume Clitoria ternatea L. by chemotactic activity. Archives of Microbiology DOI: $10.1007 / \mathrm{s} 00203-020-01815-0$

Anke H. 1977. Metabolic products of microoorganisms. Desferritriacetylfusigen, an antibiotic from Aspergillus deflectus. Journal of Antibiotics 30(2):125-128

Arora NK, Kang SC, Maheshwari DK. 2001. Isolation of siderophore-producing strains of Rhizobium meliloti and their biocontrol potential against Macrophomina phaseolina that causes charcoal rot of groundnut. Current Science. 81(6):673-677 
489

490

491

492

493

494

495

496

497

498

499

500

501

502

503

504

505

506

507

508

509

510

511

512

513

514

515

516

517

518

519

520

521

522

A. Sharma, B. N. Johri, A. K. Sharma, and B. R. Glick. 2003. Plant growth-promoting bacterium Pseudomonas sp. strain GRP3 influences iron acquisition in mung bean (Vigna radiata L. Wilzeck). Soil Biology and Biochemistry. 35(7): 887-894

Backer R, Rokem JS, Ilangumaran G, Lamont J, Praslickova D, Ricci E, Subramanian S, Smith DL. 2018. Plant growth-promoting rhizobacteria: context, mechanisms of action, and roadmap to commercialization of biostimulants for sustainable agriculture. Frontiers in Plant Sciencei. 9:1473

Banerjee MR, Yesmin L. Vessey JK. 2006. Plant-growth-promoting rhizobacteria as biofertilizers and biopesticides. Handbook of Microbial Biofertilizers Food Products Press, Binghamton, NY, USA $137-183$

Beck HC, Hansen AM, Lauritsen FR. 2003. Novel pyrazine metabolites found in polymyxin biosynthesis by Paenibacillus polymyxa. FEMS Microbiology Letters 220(1):67-73

Beneduzi A, Peres D, Costa PBD, Zanettini MHB, Passaglia LMP. 2008. Genetic and phenotypic diversity of plant-growth-promoting bacilli isolated from wheat fields in southern Brazil. Research in Microbiology 159(4):0-250

Braun V, Braun M. 2002. Iron transport and signaling in Escherichia coli. FEBS Letters 529 (1):78-85

Castellano HA, Pérez TV., Bedmar EJ, Santillana N. 2018. Purple corn-associated rhizobacteria with potential for plant growth promotion. Journal of Applied Microbiology 124(5):1254-1264

Charlang G, Ng B, Horowitz NH, Horowitz RM. 1981. Cellular and extracellular siderophores of Aspergillus nidulans and Penicillium chrysogenum. Molecular and Cellular Biology 1(2):94-100

Charlang G, Horowitz RM, Lowy PH, Ng B, Poling SM, Horowitz NH. 1982. Extracellular siderophores of rapidly growing Aspergillus nidulans and Penicillium chrysogenum. Journal of Bacteriology 150(2):785-787

Chen L, Dick WA, Streeter JG. 2000. Production of aerobactin by microorganisms from a compost enrichment culture and soybean utilization. Journal of Plant Nutrition 23(1112):2047-2060

Chen X, Cao F, Li Z, Wu T, Ran L. 2006. Role of siderophore, DAPG and PCA in suppression of conidia in Cryphonectria parasitica. Hebei Journal of Forestry and Orchard Reaserch 21(4)404-408

Chet I, Ordentlich A, Shapira R, Oppenheim AB. 1990. Mechanisms of biocontrol of soilborne plant-pathogens by rhizobacteria. Plant Soil 129(1):85-92 
523 Cho Y, Njiti VN, Chen X, Lightfoot DA, Wood AJ. 2003. Trigonelline concentration in field-

524

525

526

527

528

529

530

531

532

533

534

535

536

537

538

539

540

541

542

543

544

545

546

547

548

549

550

551

552

553

554

555

556 grown soybean in response to irrigation. Biologia Plantarum 46(3):405-410

Costacurta A, Vanderleyden J. 1995. Synthesis of phytohormones by plant-associated bacteria. Critical Reviews in Microbiology 21(1):1-18

Cruz M, Martín J, González-Menéndez V, Pérez-Victoria I, Moreno C, Tormo JR, El Aouad N, Guarro J, Vicente F, Reyes F, Bills GF. 2012. Chemical and physical modulation of antibiotic activity in Emericella species. Chemistry and Biodiversity 9(6):1095-113

Diekmann H, Zähner H. 1967. Constitution and catabolism of fusigen to delta-2anhydromevalonic acid lactone. European Journal of Biochemistry 3(2):213-215.

Diekmann H, Krezdorn E. 1975. Metabolic products of microorganisms. ferricrocin, triacetylfusigen and other sideromines from fungi of the genus Aspergillus, group Fumigatus. Archives of Microbiology 106(3):191-194

Duijff BJ, Meijer JW, Bakker PAHM, Schippers B. 1993. Siderophore-mediated competition for iron and induced resistance in the suppression of fusarium wilt of carnation by fluorescent Pseudomonas spp. Netherlands Journal of Plant Pathology 99(5-6):277-289

Emery T. 1976. Fungal ornithine esterases: relationship to iron transport. Biochemistry 15(13):2723-2728

Franco-Sierra ND, Posada LF, Santa-María G, Romero-Tabarez M, Villegas-Escobar V, Álvarez, JC. 2020. Bacillus subtilis EA-CB0575 genome reveals clues for plant growth promotion and potential for sustainable agriculture. Functional and Integrative Genomics 115

Galloway JN, Townsend AR, Erisman JW, Bekunda M, Cai Z, Freney JR, Martinelli LA, Seitzinger SP, Sutton MA. 2008. Transformation of the nitrogen cycle: recent trends, questions, and potential solutions. Science 320:889-892

Gathungu RM, Bird SS, Sheldon DP, Kautz R, Vouros P, Matson WR, Kristal. 2014. Identification of metabolites from liquid chromatography-coulometric array detection profiling: Gas chromatography-mass spectrometry and refractionation provide essential information orthogonal to LC-MS/microNMR. Analytical Biochemistry 454(2):23-32

Gazaryan IG, Lagrimini LM, Ashby GA, Thorneley RN. 1996. Mechanism of indole-3-acetic acid oxidation by plant peroxidases: anaerobic stopped-flow spectrophotometric studies on horseradish and tobacco peroxidases. Biochemical Journal 313(3):841-847

Glick BR. 2012. Plant growth-promoting bacteria: mechanisms and applications. Scientifica 2012:1-15 
557

558

559

560

561

562

563

564

565

566

567

568

569

570

571

572

573

574

575

576

577

578

579

580

581

582

583

584

585

586

587

588

589

590

591

Glickmann E, Dessaux Y. 1995. A critical examination of the specificity of the salkowski reagent for indolic compounds produced by phytopathogenic bacteria. Applied and Environmental Microbiology 61(2):793-796

González-Ruiz V, Mussardo P, Corda E, Girotti S, Martín MA. 2010. Liquid chromatographic analysis of the anticancer alkaloid luotonin a and some new derivatives in human serum samples. Journal of Separation Science 33(14):2086-2093

Guerinot ML. 1994. Microbial iron transport. Annual Review of Microbiology 48(1):743-772

Gupta V, Roper MM, Roget DK. 2006. Potential for non-symbiotic $\mathrm{N}_{2}$ fixation in different agroecological zones of southern Australia. Australian Journal of Soil Research. 44:343354

Haas D, Defago G. 2005. Biological control of soil-borne pathogens by Fluorescent pseudomonads. Nature Reviews Microbiology 3(4):307-319

Hossain MB, Eng-Wilmot DL, Loghry RA, Dick VDH. 1980. Circular dichroism, crystal structure, and absolute configuration of the siderophore ferric $\mathrm{N}, \mathrm{N}, \mathrm{N}$ "-triacetylfusarinine, $\mathrm{FeC}_{39} \mathrm{H}_{57} \mathrm{~N}_{6} \mathrm{O}_{15}$. Journal of the American Chemical Society 102(18):5766-5773

Hutchins DA, Witter AE, Butler A, Luther GW. 1999. Competition among marine phytoplankton for diferent chelated iron species. Nature 400(6747):858-861

Ji C, Juárez-Hernández RE, Miller MJ. 2012. Exploiting bacterial iron acquisition: siderophore conjugates. Future Medicinal Chemistry 4(3):297-313

Kalinowski DS, Richardson DR. 2005. The evolution of iron chelators for the treatment of iron overload disease and cancer. Pharmacological Reviews 57(4):547-583

Kazamia E, Sutak R, Paz-Yepes J, Dorrell RG, Vieira FRJ, Mach J, Morrissey J, Leon S, Lam F, Pelletier E, Camadro JM, Bowler C, Lesuisse E. 2018. Endocytosis-mediated siderophore uptake as a strategy for $\mathrm{Fe}$ acquisition in diatoms. Science Advances 4(5): eaar4536

Katzy EI, Iosipenko AD, Egorenkov DA, Zhuravleva EA, Panasenko VI, Ignatov VV. 1990. Involvement of Azopirillum brasilense plasmid DNA in the productio of indole acetic acid. FEMS Microbiology Letters 72(1):1-4

Khan MS, Gao J, Chen X, Zhang M, Yang F, Du Y, Moe TS, Munir I, Xue J, Zhang X. 2020. Isolation and characterization of plant growth-promoting endophytic bacteria Paenibacillus polymyxa SK1 from Lilium lancifolium. Biomed Research International

Kodani S, Komaki, Suzuki M, Kobayakawa F, Hemmi H. 2015. Structure determination of a siderophore peucechelin from Streptomyces peucetius. Biometals 28(5):791-801

Kovács K, Sharma VK, Kamnev A A, Kuzmann E, Homonnay Z, Vértes A. 2008. Water and time dependent interaction of iron(III). Structural Chemistry 19(1):109-114

Peer] reviewing PDF | (2019:10:42693:2:0:NEW 24 May 2020) 
592

593

594

595

596

597

598

599

600

601

602

603

604

605

606

607

608

609

610

611

612

613

614

615

616

617

618

619

620

621

622

623

624

Kretzschmar T, Pelayo MAF, Trijatmiko KR, Gabunada LFM, Alam R, Jimenez R, Mendioro MS, Slamet-Loedin IH, Sreenivasulu N, Bailey-Serres J, Ismail AM, Mackill DJ, Septiningsih EM. 2015. A trehalose-6-phosphate phosphatase enhances anaerobic germination tolerance in rice. Nature Plants 1(9):15124

Kumari M, Thakur IS. 2018. Biochemical and proteomic characterization of Paenibacillus sp. ISTP10 for its role in plant growth promotion and in rhizostabilization of cadmium. Bioresource Technology Reports 55(5):694-699

Lambrecht M, Okon Y, Broek AV, Vanderleyden J. 2000. Indole-3-acetic acid: a reciprocal signalling molecule in bacteria-plant interactions. Trends in Microbiology 8(7):298-300

Lebuhn M, Heulin T, Hartmann A. 1997. Production of auxin and other indolic and phenolic compounds by Paenibacillus polymyxa strains isolated from different proximity to plant roots. FEMS Microbiology Ecology 22(4):325-334

Li E, Jiang L, Guo L, Zhang H, Che Y. 2008. Pestalachlorides A-C, antifungal metabolites from the plant endophytic fungus Pestalotiopsis adusta. Bioorganic and Medicinal Chemistry 16(17): 7894-7899

Li YB, Li YL, Zhang H, Wang M, Chen S. 2019. Diazotrophic Paenibacillus beijingensis BJ18 provides nitrogen for plant and promotes plant growth, nitrogen uptake and metabolism. Frontiers in Microbiology 10:1119

Liu H, Carvalhais LC, Crawford M, Singh E, Dennis PG, Pieterse CMJ, Schenk PM. 2017. Inner Plant values: diversity, colonization and benefits from endophytic bacteria. Frontiers in Microbiology 8:1-17

Liu L, Bao L, Wang L, Ma K, Han J, Yang Y, Liu R, Ren J, Yin W, Wang W, Liu HW. 2018. Asperorydines A-M: Prenylated tryptophan-derived alkaloids with neurotrophic effects from Aspergillus oryzae. The Journal of Organic Chemistry 83(2):812-822

Liu Y, Wang Z, Bilal M, Hu H, Wang W, Huang X, Peng H, Zhang X. 2018. Enhanced fluorescent siderophore biosynthesis and loss of phenazine-1-carboxamide in phenotypic variant of Pseudomonas chlororaphis HT66. Frontiers in Microbiology 9:759

Lu LG, Zeng MD, Mao YM, Li JQ, Wan MB, Li CZ, Chen CW, Fu QC, Wang JY, She WM, Cai XJ, Ye J, Zhou XQ, Wang H, Wu SM, Tang MF, Zhu JS, Chen WX, Zhang HQ. 2003. Oxymatrine therapy for chronic hepatitis B: A randomized double-blind and placebo-controlled multi-center trial. World Journal of Gastroenterology 9(11):2480-2483

Lucy M, Reed E, Glick BR. 2004. Applications of free living plant growth-promoting rhizobacteria. Antonie van Leeuwenhoek. 86(1):1-25. 
625 Ma K, Ren J, Han J, Bao L, Liu H. 2014. Ganoboninketals A-C, antiplasmodial 3,4-seco-27626 norlanostane triterpenes from Ganoderma boninense Pat. Journal of Natural Products 77(8):1847-1852

Mao X, Tang L, Tan T, Wan Y. 2014. Determination of plant growth regulators in pears by

629 microwave-assisted extraction and liquid chromatography with electrospray ionization mass spectrometry. J Sep Sci. 37(11):1352-8

631

Menéndez E, Pérez-Yépez J, Hernández M, Rodríguez-Pérez A, Velázquez E, León-Barrios

632 M. 2020. Plant growth promotion abilities of phylogenetically diverse Mesorhizobium

633

634

635

636

637

638

639

640

641

642

643

644

645

646

647

648

649

650

651

652

653

654

655

656

657

658

659 strains: effect in the root colonization and development of tomato seedlings. Microorganisms 8(3):412

Miethke M, Marahiel MA. 2007. Siderophore-based iron acquisition and pathogen control. Microbiology and Molecular Biology Reviews 71(3):413-451

Minorsky PV. 2002. Trigonelline: a diverse regulator in plants. Plant physiology 128(1):7-8

Murashige T, Skoog F. 1962. A revised medium for rapid growth and bio assays with tobacco tissue cultures. Physiologia Plantarum 15(3):473-497

O’Sullivan DJ, O’Gara F. 1992. Traits of fluorescent Pseudomonas spp. involved in suppression of plant root pathogens. Microbiological Reviews. 56(4): 662-676.

Pari L, Murugan P. 2004. Protective role of tetrahydrocurcumin against erythromycin estolateinduced hepatotoxicity. Pharmacological Research 49(5):481-486

Pallab M, Shubhasis D, Soumya C, Balaram G, Chiranjit S, Jasmina K, Tapan P. 2019. Simultaneous determination and quantitation of diosmetin and hesperetin in human plasma by liquid chromatographic mass spectrometry with an application to pharmacokinetic studies. Journal of Chromatographic Science 57(5):451-461

Park KR, Nam D, Yun HM, Lee SG, Jang HJ, Sethi G. Cho SK, Ahn KS. 2011. $\beta$ caryophyllene oxide inhibits growth and induces apoptosis through the suppression of $\mathrm{PI} 3 \mathrm{~K} / \mathrm{AKT} / \mathrm{mTOR} / \mathrm{S} 6 \mathrm{~K} 1$ pathways and ROS-mediated MAPKs activation. Cancer Letters 312(2): 0-188

Prasad YU, Alexander I, Regina F, You DG, Dirk W, Patrick G, Hans-Michael H, Mark S, John EL. 2014. The sucrose-trehalose 6-phosphate (Tre6p) nexus: specificity and mechanisms of sucrose signalling by Tre6p. Journal of Experimental Botany 64(4):1051-68

Ratledge C, Dover LG. 2000. Iron metabolism in pathogenic bacteria. Annual Review of Microbiology 54(1):881-941

Rogerio AP, Andrade EL, Leite, DFP, Figueiredo CP, Calixto JB. 2009. Preventive and therapeutic anti-inflammatory properties of the sesquiterpene $\alpha$-humulene in experimental airways allergic inflammation. British Journal of Pharmacology 158(4):1074-1087 
660

661

662

663

664

665

666

667

668

669

670

671

672

673

674

675

676

677

678

679

680

681

682

683

684

685

686

687

688

689

690

691

692

693

694

Rustamova N, Bobakulov K, Begmatov N, Turak A, Yili A, Aisa HA. 2019. Secondary metabolites produced by endophytic Pantoea ananatis derived from roots of Baccharoides anthelmintica and their effect on melanin synthesis in murine B16 cells. Natural product research 10:1-6

Sayer JM, Emery TF. 1968. Structures of the naturally occurring hydroxamic acids, fusarinines A and B. Biochemistry 7(1):184-190

Schippers BA, Bakker AW, Bakker PAHM. 2003. Interactions of deleterious and beneficial rhizosphere microorganisms and the effect of cropping practices. Annual Review of Phytopathology 25(1): 339-358

Schrettl M, Bignell E, Kragl C, Sabiha Y, Loss O, Eisendle M, Wallner A, Arst HN, Haynes K, Haas H. 2007. Distinct roles for intra- and extracellular siderophores during Aspergillus fumigatus infection. PLoS Pathogens 3(9):e128

Schwyn B, Neilands JB. 1987. Universal chemical-assay for the detection and determination of siderophores. Analytical Biochemistry 160(1):47-56

Sheng MM, Jia HK, Zhang GY, Zeng LN, Zhang TT, Long YH, Lan J, Hu ZQ, Zeng Z, Wang B, Liu HM. 2020. Siderophore production by rhizosphere biological control bacteria Brevibacillus brevis GZDF3 of Pinellia ternata and its antifungal effects on Candida albicans. Journal of Microbiology and Biotechnology

Shenker M, Oliver I, Helmann M, Hadar Y, Chen Y. 1992. Utilization by tomatoes of iron mediated by a siderophore produced by Rhizopus arrhizus. Journal of Plant Nutrition 15(10):2173-2182

Shi H, Li Y, Li P, Wang Z, Chen S. 2016. Effect of nitrogen-fixing Paenibacillus spp.on wheat yield. Journal of China Agricultural University 21(6):52-55

Shuangya C, Yongxiang Z, Xiangqun C. 2003. Mechanism of three bacterial strains to inhibit Stagonospora curtisii causing leaf spot of Narcissus tazetta. Chinese Journal of Biological Control 19(1):11-15

Song G, Luo Q, Qin J, Wang L, Shi Y, Sun C. 2006. Effects of oxymatrine on proliferation and apoptosis in human hepatoma cells. Colloids and Surfaces B Biointerfaces 48(1):1-5

Tramontano WA, Jouve D. 1997. Trigonelline accumulation in salt-stressed legumes and the role of other osmoregulators as cell cycle control agents. Phytochemistry 44(6):1037-1040

Trivedi MK, Gangwar M, Mondal SC, Jana S. 2017. Protective effects of tetrahydrocurcumin (THC) on fibroblast and melanoma cell lines in vitro: it's implication for wound healing. Journal of Food Science and Technology 54(5):1137-1145

Wang L, Li J, Li Q, Chen S. 2013. Paenibacillus beijingensis sp nov., a nitrogen-fixing species isolated from wheat rhizosphere soil. Antonie van Leeuwenhoek 105(2):675-683 
695 Weyers JDB, Paterson NW. 2001. Plant hormones and the control of physiological processes.

696

697

698

699

700

701

702

703

704

705

706

707

708

709

710

711

712

713

714

715

716 New Phytologist 152(3):375-407

Wingler A, Delatte TL, O"Hara LE, Primavesi LF, Jhurreea D, Schluepmann PH. 2012. Trehalose 6-phosphate is required for the onset of leaf senescence associated with high carbon availability. Plant Physiology 158(3):1241-1251

Xie B, Xu K, Zhao H, Chen S. 2005. Isolation of transposon mutants from Azospirillum brasilense Yu62 and characterization of genes involved in indole-3-acetic acid biosynthesis. FEMS Microbiology Letters 248(1):57-63

Xie J, Shi H, Du Z, Wang T, Liu X, Chen S. 2016. Comparative genomic and functional analysis reveal conservation of plant growth promoting traits in Paenibacillus polymyxa and its closely related species. Scientific Report 6(1):21329

Yang DP, Michel L, Chaumont JP, Millet-Clerc J. 1999. Use of caryophyllene oxide as an antifungal agent in an in vitro experimental model of onychomycosis. Mycopathologia 148(2):79-82

Yahara S, Uda N, Yoshio E, Yae E. 2004. Steroidal alkaloid glycosides from tomato (Lycopersicon esculentum). Journal of Natural Products 67(3):500-502

Yehuda Z, Shenker M, Romheld V, Marschner H, Chen Y. 1996. The role of ligand exchange in the uptake of iron from microbial siderophores by gramineous plants. Plant physiology 112(3):1273-1280

Yuquan X, Hong G, Genglei T, Xinde Z. 1999. Siderophore production and their activity against Piricularia oryzae by Pseudomonas JKD-2. Microbiology 26(3):180-183 
Figure 1

untargeted metabolomics profiling of $P$. triticisoli BJ-18

A: Number of compounds of different types; B: Number of compounds in different molecular weight.

A

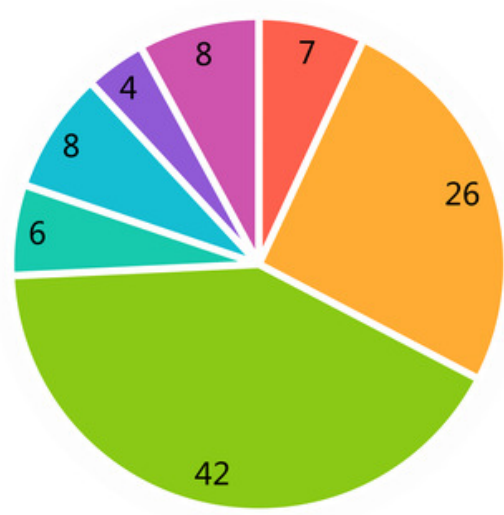

- carbohydrates

= amino acids and peptides

- alcohols, aldehydes, ketones, fatty acids and lipids

nucleic acids

vitamins

- alkaloids

- cyclics

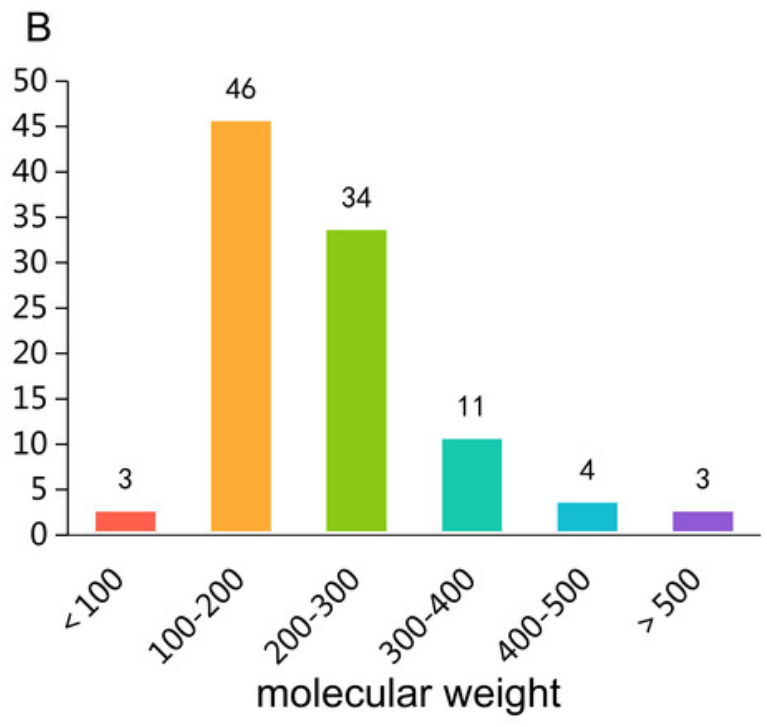


Figure 2

Compounds isolated from $P$. triticisoli BJ-18

Six compounds were isolated from $P$. triticisoli BJ-18, including three classical siderophore fusarinines identified as (1) deshydroxylferritriacetylfusigen, (2) desferritriacetylfusigen and (3) triacetylfusigen, and three indolic acids identified as (4) paenibacillic acid A, (5) 3indoleacetic acid(IAA), and (6) 3-indolepropionic acid (IPA).

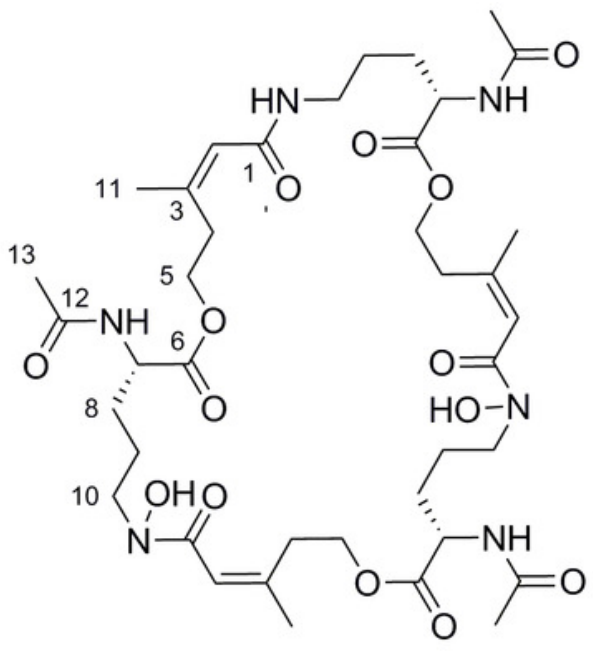

1

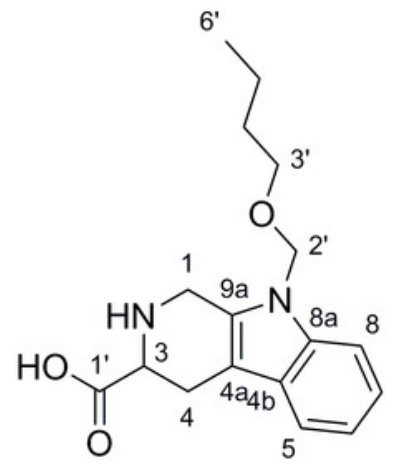

4

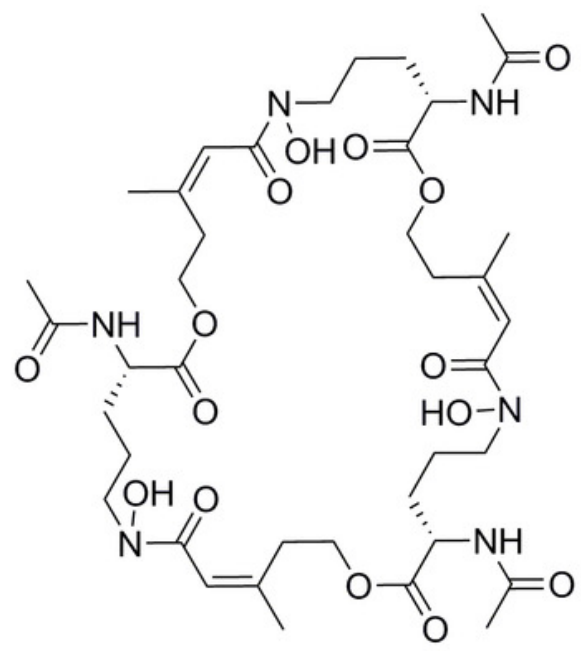

2

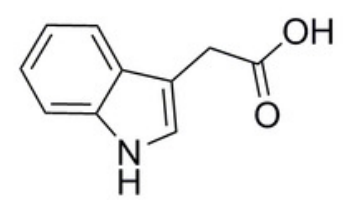

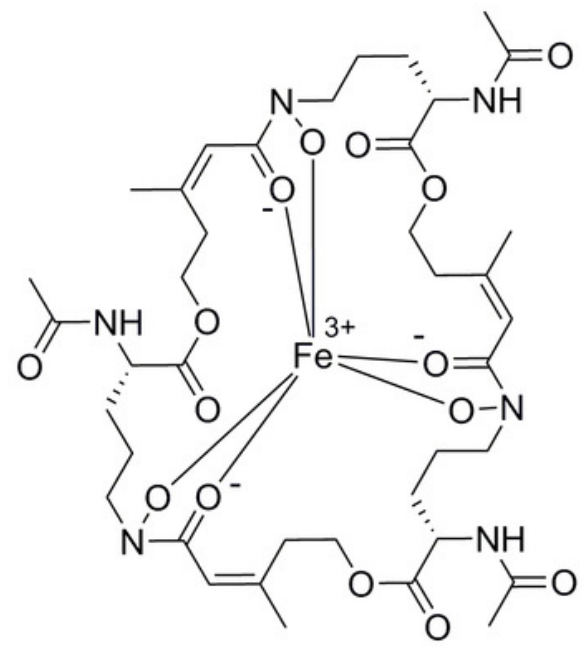

3<smiles>O=C(O)CCc1c[nH]c2ccccc12</smiles> 
Figure 3

Key ${ }^{1} \mathrm{H}-{ }^{1} \mathrm{H}$ COSY and HMBC correlations of compounds 1 and 4

${ }^{1} \mathrm{H}-{ }^{1} \mathrm{H}$ COSY spectra (DMSO- $d_{6}, 8 \mathrm{MHz}$ ); HMBC spectra (DMSO- $d_{6}, 8 \mathrm{MHz}$ )

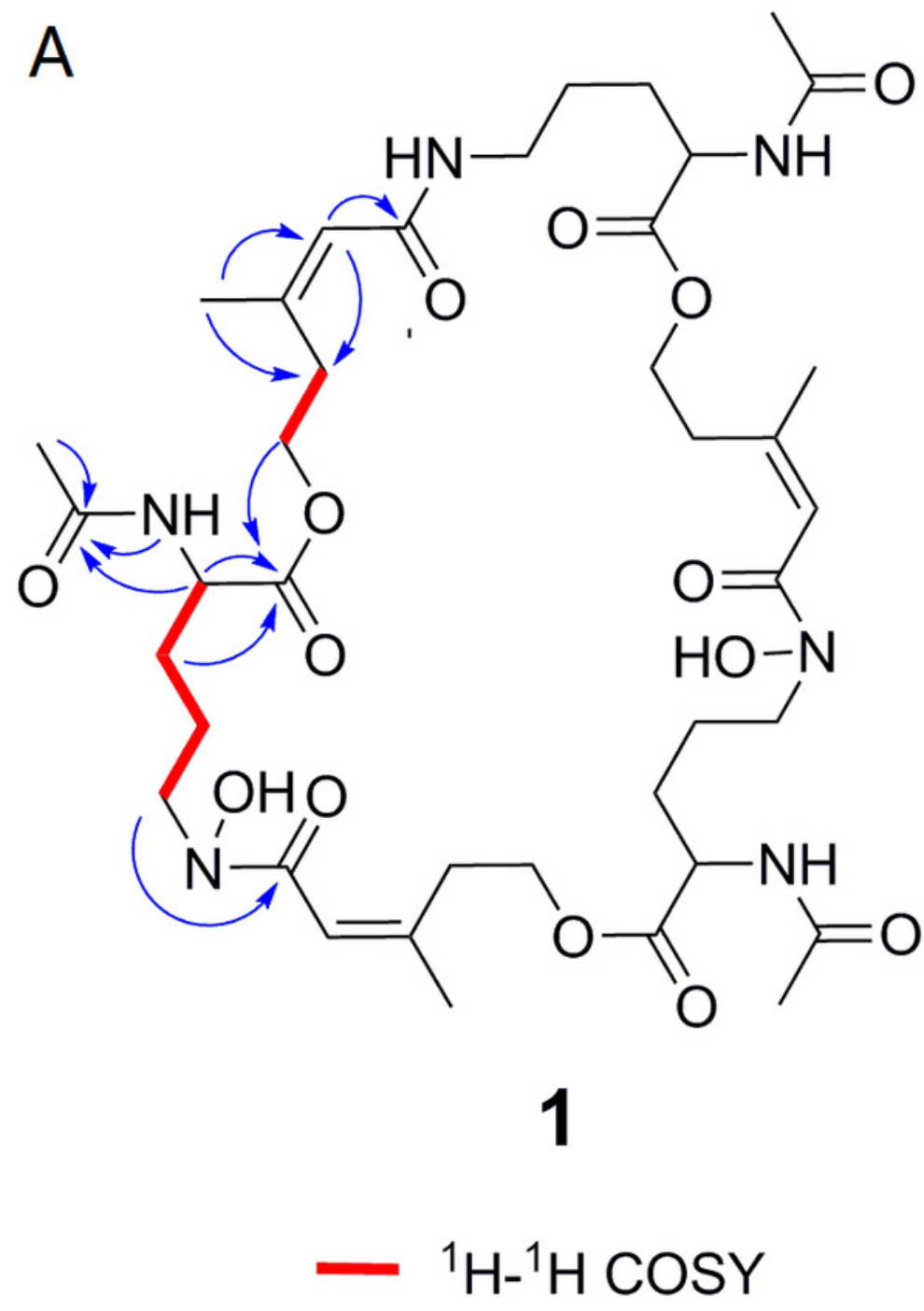

B

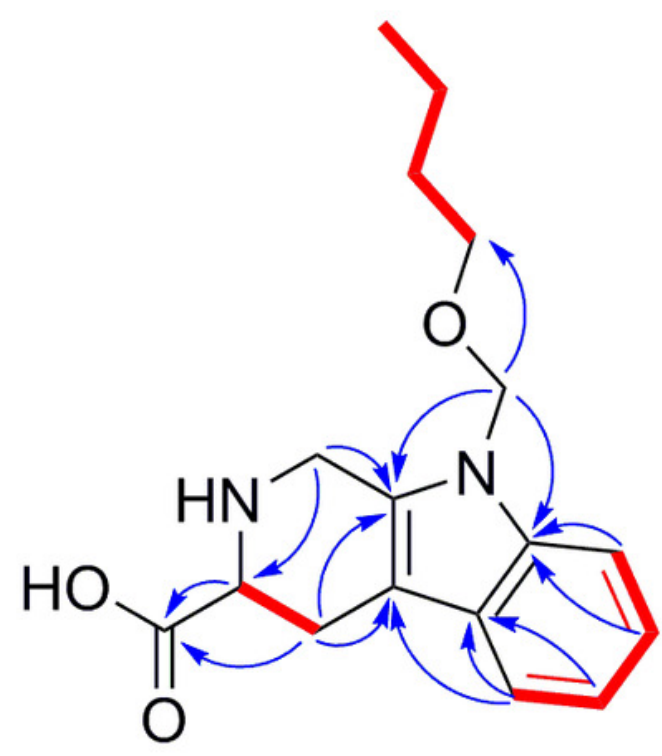




\section{Figure 4}

Experimental ECD spectra of 4 and its calculated ECD spectra of related simplified possible stereoisomers $4 a$ and $4 b$.

Experimental ECD spectra of 4 was recorded in methanol. Systematic conformation analysis of 4a was conducted with CONFLEX using the MMFF94 molecular mechanics force field. Optimization with DFT calculation at the B3LYP/6-31G(d) level in MeOH by the Gaussian09 program afforded the MMFF minima. At the B3LYP/6-31G(d) level, the exciting states were calculated using time-dependent density-functional theory (TDDFT) methodology for $4 a$. The overall ECD spectra were then produced based on Boltzmann weighting of each conformer. 


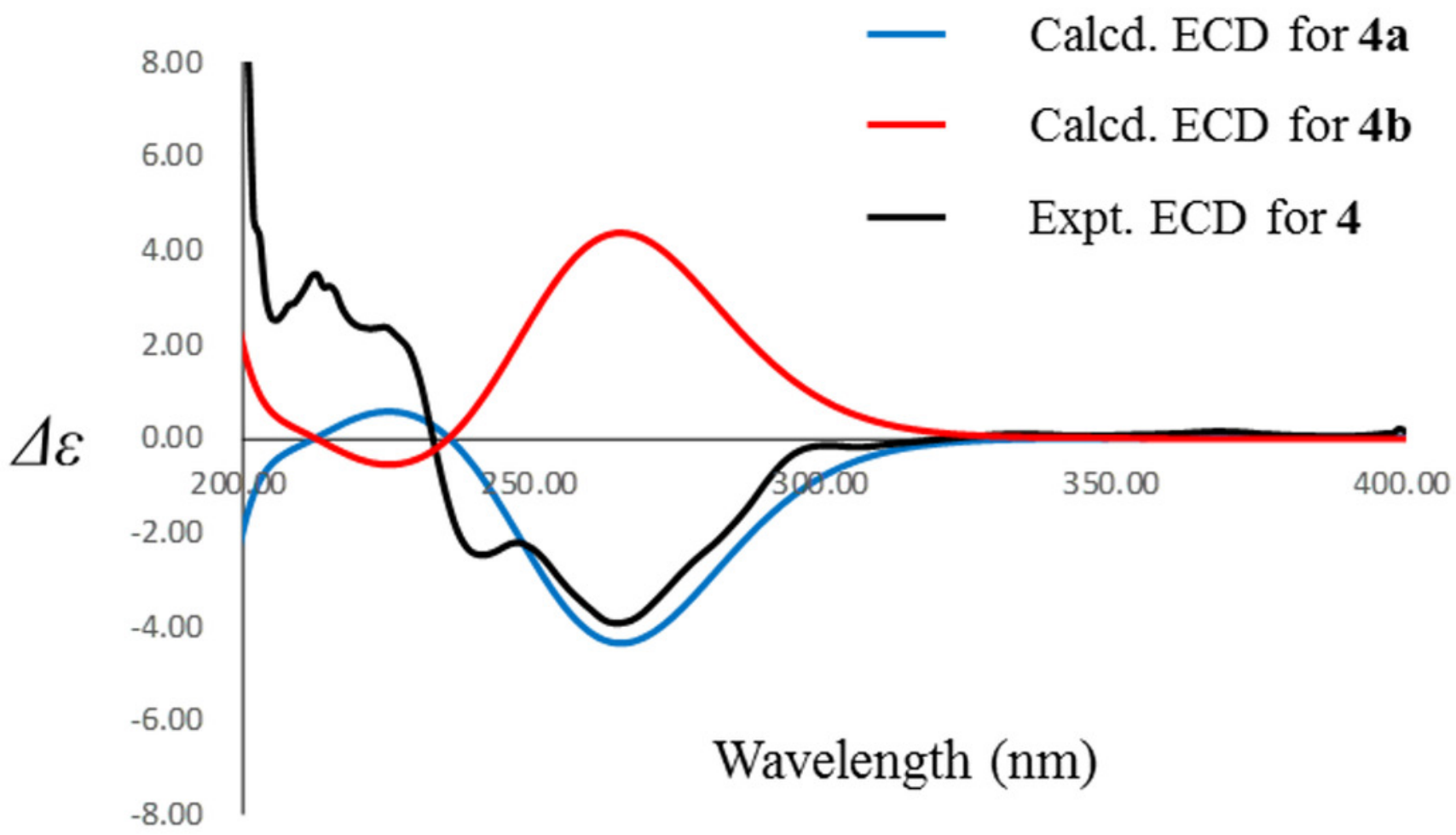

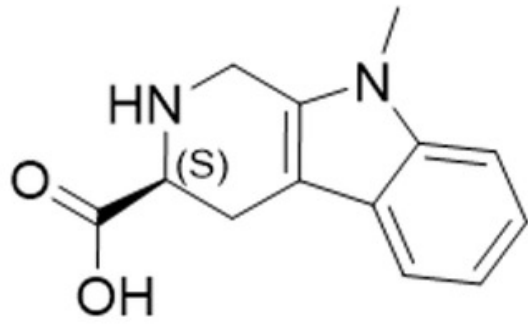

$4 a$

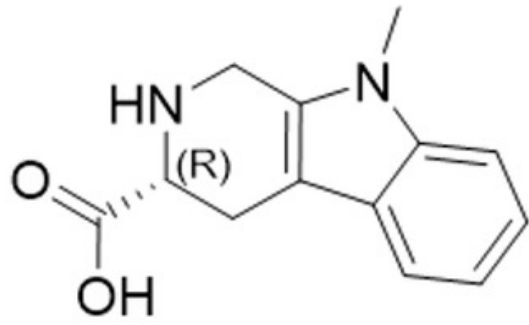

4b 


\section{Figure 5}

Plant growth-promoting capacity of indolic compounds on Arabidopsis thaliana

Seeds of Arabidopsis thaliana var. Columbia were used as plant material, and were incubated at $25 \pm 2{ }^{\circ} \mathrm{C}$ under cool fluorescent light (2000 lux $16 \mathrm{~h} /$ day photoperiod) for 14 days.

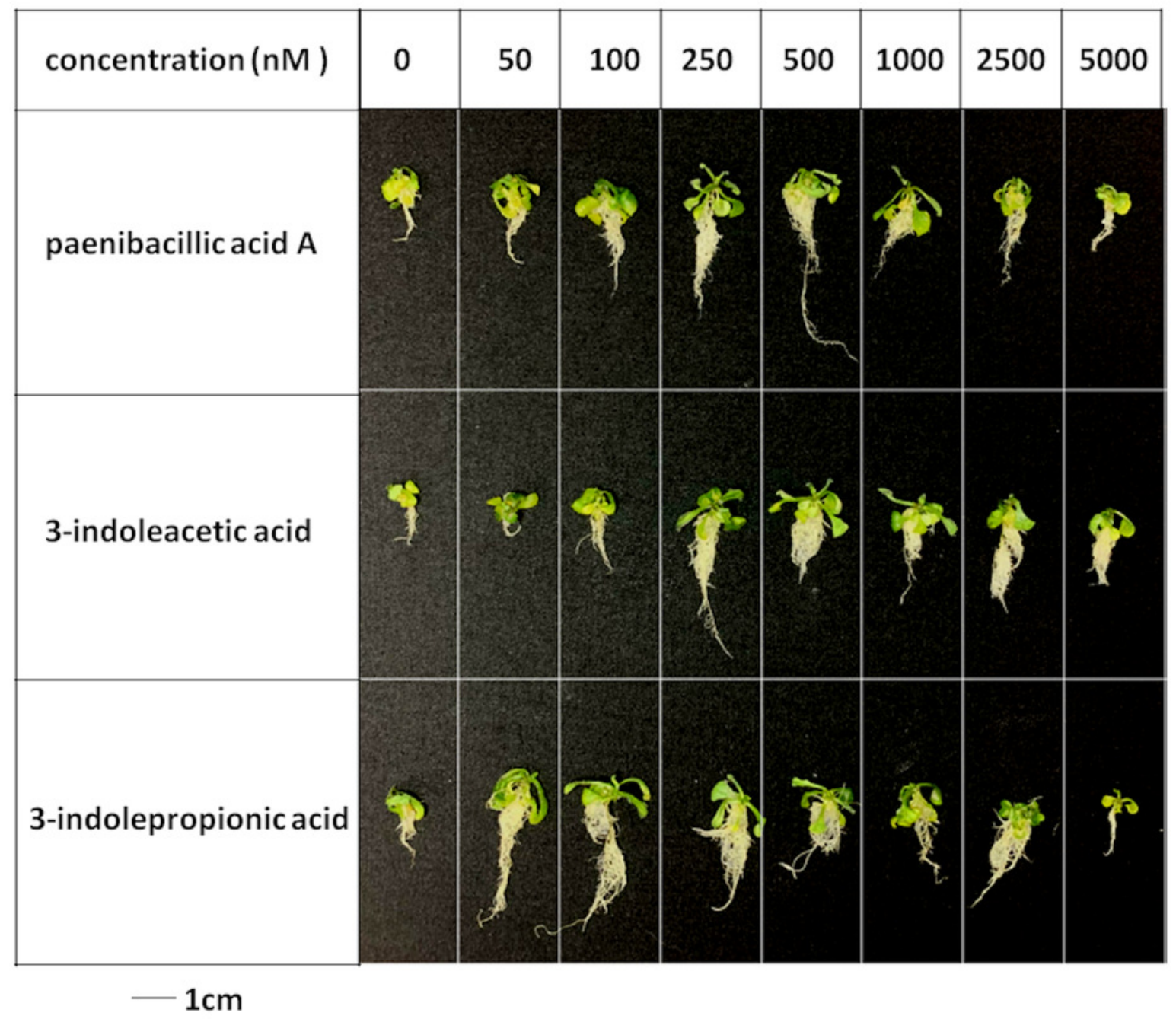


Figure 6

Comparison of plant growth-promoting ability of indolic compounds

At least ten Arabidopsis strains were cultured in each group of treatments. The cultures were incubated at $25 \pm 2{ }^{\circ} \mathrm{C}$ under cool fluorescent light (2000 lux $16 \mathrm{~h} /$ day photoperiod) for 14 days. 

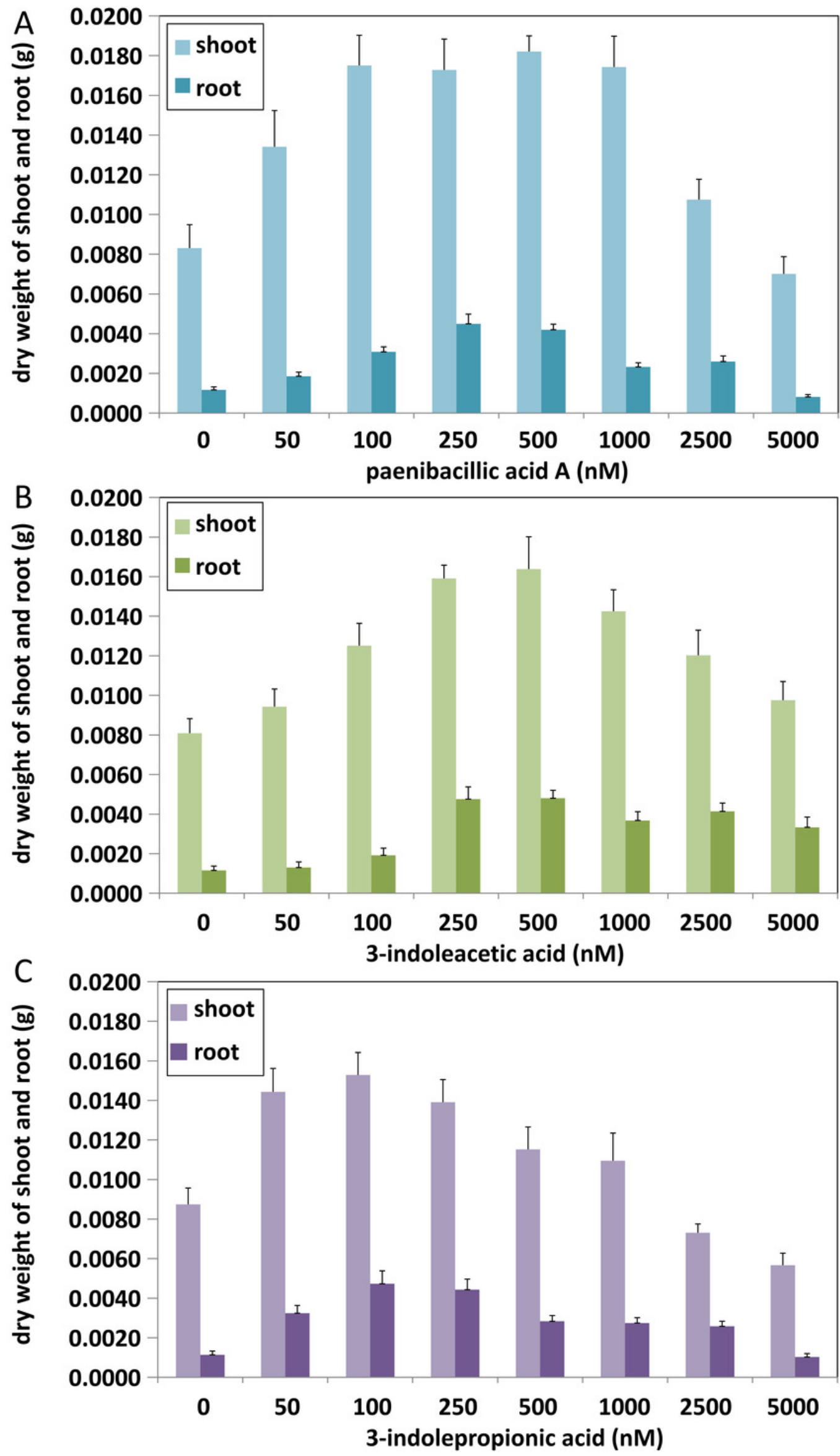


\section{Figure 7}

P. triticisoli BJ-18 promotes plant growth by several mechanisms

The orange squares represent plant growth regulators such as T6P, betaine and trigonelline. The purple ring represents fusarinines and the red dot represents iron atoms. The blue triangle indicates indole acids. Red radial circles represent plant pathogens. Six-component structure representing nitrogenase.

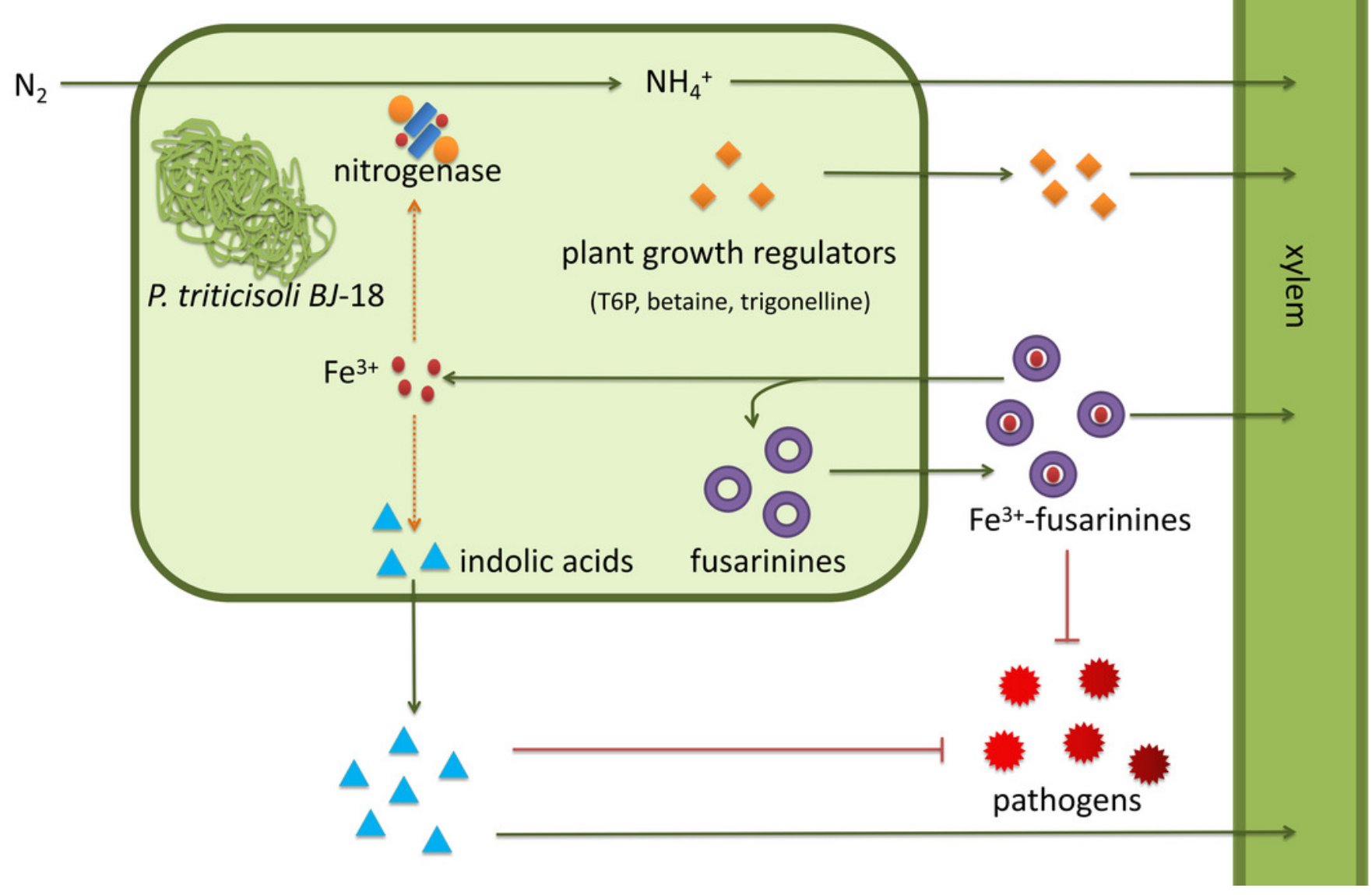




\section{Table 1 (on next page)}

NMR data of compound 1 in DMSO- $d_{6}$

${ }^{1}$ Recorded at $125 \mathrm{MHz} ;{ }^{2}$ Recorded at $500 \mathrm{MHz}$. 
Table 1. NMR data of compound 1 in DMSO- $d_{6}$

\begin{tabular}{lll}
\hline Pos. & $\boldsymbol{\delta}_{\mathbf{C}}{ }^{1}$ & $\boldsymbol{\delta}_{\mathbf{H}}{ }^{2}$, mult $(\boldsymbol{J}$ in Hz) \\
1 & 166.0 & \\
2 & 117.5 & $6.31, \mathrm{~s}$ \\
3 & 150.0 & \\
4 & 31.9 & 2.80, br. s \\
5 & 63.1 & $4.17, \mathrm{~m}$ \\
& & $4.12, \mathrm{~m}$ \\
6 & 172.1 & \\
7 & 51.8 & $4.19, \mathrm{~m}$ \\
8 & 28.0 & $1.65, \mathrm{~m}$ \\
9 & 23.0 & $1.53, \mathrm{~m}$ \\
10 & 46.3 & $3.51 \mathrm{br} . \mathrm{s}$ \\
11 & 25.3 & $1.87, \mathrm{~s}$ \\
12 & 169.5 & \\
13 & 22.3 & $1.84, \mathrm{~s}$ \\
& $\mathrm{~N}-\mathrm{OH}$ & $9.70, \mathrm{br} . \mathrm{s}$ \\
& $\mathrm{N}-\mathrm{H}$ & $8.20, \mathrm{~d}(7.5)$ \\
\hline
\end{tabular}

3

4 
Table 2 (on next page)

NMR data of compound 4 in DMSO- $d_{6}$

${ }^{1}$ Recorded at $125 \mathrm{MHz} ;{ }^{2}$ Recorded at $500 \mathrm{MHz}$ 
Table 2. NMR data of compound 4 in DMSO- $d_{6}$

\begin{tabular}{|c|c|c|}
\hline Pos. & $\delta_{\mathrm{C}}{ }^{1}$ & $\delta_{\mathrm{H}}^{2}$,mult $(J$ in $\mathrm{Hz})$ \\
\hline \multirow[t]{2}{*}{1} & 39.5 & $4.35, \mathrm{~d}(15.7)$ \\
\hline & & $4.21, \mathrm{~d}(15.7)$ \\
\hline 3 & 56.1 & $3.63, \mathrm{dd}(10.3,5.0)$ \\
\hline \multirow[t]{2}{*}{4} & 22.9 & $3.13, \mathrm{dd}(15.3,5.0)$ \\
\hline & & $2.84, \mathrm{dd}(15.3,10.4)$ \\
\hline $4 a$ & 108.2 & \\
\hline $4 \mathrm{~b}$ & 126.2 & \\
\hline 5 & 118.1 & $7.47, \mathrm{~d}(7.5)$ \\
\hline 6 & 119.7 & $7.07, \mathrm{t}(7.5)$ \\
\hline 7 & 121.9 & $7.17, \mathrm{t}(7.5)$ \\
\hline 8 & 109.8 & $7.55, \mathrm{~d}(7.5)$ \\
\hline $8 \mathrm{a}$ & 137.2 & \\
\hline $9 \mathrm{a}$ & 129.4 & \\
\hline $1^{\prime}$ & 170.0 & \\
\hline $2^{\prime}$ & 72.3 & $5.46, \mathrm{~s}$ \\
\hline $3^{\prime}$ & 67.1 & $3.30, \mathrm{~m}$ \\
\hline $4^{\prime}$ & 31.0 & $1.40, \mathrm{~m}$ \\
\hline $5^{\prime}$ & 18.8 & $1.22, \mathrm{~m}$ \\
\hline $6^{\prime}$ & 13.6 & $0.78, \mathrm{t}(7.4)$ \\
\hline
\end{tabular}

${ }^{1}$ Recorded at $125 \mathrm{MHz} ;{ }^{2}$ Recorded at $500 \mathrm{MHz}$ 


\section{Table 3 (on next page)}

\section{Antimicrobial activity of compound 1-6}

Gentamicin, ampicillin, streptomycin sulfate and amphotericin B were used as positive controls against $E$. coli, S. aureus, $B$. subtilis and $C$. albicans, respectively. The compounds were tested at concentrations of 5 $\mu \mathrm{M}, 10 \mu \mathrm{M}$ and $20 \mu \mathrm{M}$. The $\mathrm{IC}_{50}$ was calculated using the Spearman-Karber's method. The horizontal line " -" indicated that the compound had no antibacterial activity against the indicator strain. 
Table 3. Antimicrobial activity of compounds 1-6

\begin{tabular}{|c|c|c|c|c|}
\hline $\mathrm{IC}_{50}(\mu \mathrm{M})$ & E. coli & S. aureus & B. subtilis & C. albicans \\
\hline compound 1 & 6.8 & 5.2 & 8.8 & -- \\
\hline compound 2 & 4.7 & 4.3 & 6.4 & -- \\
\hline compound 3 & -- & -- & -- & -- \\
\hline compound 4 & -- & 7.4 & -- & -- \\
\hline compound 5 & -- & -- & -- & -- \\
\hline compound 6 & -- & -- & -- & -- \\
\hline Pos. & 1.9 & 2.1 & 2.3 & 2.2 \\
\hline
\end{tabular}

5 Gentamicin, ampicillin, streptomycin sulfate and amphotericin B were used as positive controls against E. coli, S. aureus, B. subtilis and C. albicans, respectively.

6 The compounds were tested at concentrations of $5 \mu \mathrm{M}, 10 \mu \mathrm{M}$ and $20 \mu \mathrm{M}$. The $\mathrm{IC}_{50}$ was calculated using the Spearman-Karber's method. The horizontal line "--

7 " indicated that the compound had no antibacterial activity against the indicator strain. 